\title{
ReVisão de literatura Receptores neurais e a doença de Alzheimer: uma revisão sistemática da literatura sobre as famílias de receptores mais associadas a doença, suas funções e áreas de expressão
}

\author{
Neural receptors and Alzheimer's disease: a systematic review \\ of the literature on receptor families most associated with \\ the disease, their functions and expression areas \\ Alice Barros Câmara' \\ https://orcid.org/0000-0002-1974-4363
}

\section{RESUMO}

Objetivo: $O$ artigo tem como objetivo determinar as famílias de receptores mais estudadas, envolvidas com a doença de Alzheimer, assim como determinar a região do sistema nervoso na qual mais tipos de receptores são expressos e quais funções dos receptores estão predominantemente associadas com a patologia em questão. $\mathrm{O}$ artigo busca mostrar os modelos e métodos mais utilizados nessas pesquisas, resumindo alguns achados e discutindo o impacto desses estudos no conhecimento científico. Métodos: Esta revisão utilizou-se de uma metodologia sistemática (Prospero; ID 141957). Resultados: Pode-se constatar que os receptores de transcrição nuclear foram os mais estudados. A maior parte desses receptores se expressa no córtex cerebral e hipocampo. Adicionalmente, a maioria das pesquisas avaliou os receptores relacionados com os efeitos benéficos na doença. A eliminação da proteína amiloide ou o bloqueio de vias relacionadas à síntese dessa proteína foram as principais funções desempenhadas por esses receptores. Por fim, as técnicas de imunoistoquímica e reação em

\section{Palavras-chave}

Receptores neurais, doença de Alzheimer, proteína beta-amiloide. cadeia de polimerase em tempo real (RT-PCR), respectivamente, foram as mais utilizadas, e os roedores consistiram no principal modelo de estudo. Conclusões: Os receptores de transcrição nuclear, o córtex cerebral, o hipocampo, a micróglia e a proteína beta-amiloide mostraram importância na patogênese da doença de Alzheimer neste estudo.

\section{ABSTRACT}

Objective: The article aims to find the receptors family involved with Alzheimer's disease most studied as well as the tissue that most receptors are expressed. This study also aims to determine the functions predominantly associated with the pathology. In addition, the work seeks to show the models and techniques most used, as well as summarize the findings and discuss the impact of these studies on scientific knowledge. Methods: This review addressed a systematic methodology (Prospero; ID 141957). Results: It can be seen that nuclear transcription receptors were the most studied. Most of these receptors are expressed in the cerebral cortex and hippocampus. Additionally, a great number of studies evaluated the re-

1 Universidade Federal do Rio Grande do Norte (UFRN), Departamento de Biofísica e Farmacologia, Natal, RN, Brasil. 


\section{Keywords}

Neural receptors, Alzheimer's disease, amyloid beta protein. ceptors related to beneficial effects in the disease. The depletion of amyloid protein or the blockade of pathways related to its synthesis were the main functions performed by these receptors. Finally, immunohistochemistry and RT-PCR techniques, respectively, were the most used and the rodents were the main study model. Conclusions: Nuclear transcription receptors, cerebral cortex and hippocampus, microglia, and amyloid beta protein have shown significant importance in the pathogenesis of Alzheimer's disease in this study.

\section{INTRODUÇÃO}

A doença de Alzheimer (DA) é uma patologia multifatorial e de causa idiopática, e fatores genéticos e ambientais podem influenciar na sua progressão. Alguns fatores de risco estão envolvidos no desenvolvimento da DA, tais como idade avançada, fatores genéticos, traumatismo craniano, entre outros ${ }^{1}$. Estudos demonstraram que o mais prevalente fator de risco da DA é o alelo $\varepsilon 4$ da apolipoproteína E². Os principais achados neuropatológicos da doença consistem na deposição de placas de proteína beta-amiloide (APP), acúmulo de emaranhados neurofibrilares hiperfosforilados, inflamação mediada pela neuróglia, desregulação da sinalização de neurotransmissores, atrofia cerebral e alterações neuronais ${ }^{3-6}$.

As transformações intracelulares no sistema nervoso central (SNC) acarretam um estado emocional prejudicado, perda de sinapses e morte neuronal, agravando o declínio cognitivo progressivamente ${ }^{7}$. Os sintomas da lenta e progressiva neurodegeneração foram descritos em 1906 pelo neurologista Alois Alzheimer, no entanto a doença pode se desenvolver clinicamente silenciosa². A DA é responsável por acentuada morbidade e mortalidade devido à dificuldade do tratamento e aos danos irreversíveis. Em alguns casos, há estabilização da condição e o indivíduo consegue postergar sua expectativa de vida por anos'. Relativamente ao tratamento, existem apenas quatro medicamentos no mercado para o tratamento paliativo da DA: três inibidores da acetilcolinesterase (AChE) - donepezila, rivastigmina e galantamina - e um antagonista do receptor N-metil-D-aspartato (NMDA) - memantina ${ }^{8}$.

A DA é o distúrbio neurodegenerativo crônico e incurável mais recorrente na humanidade?. Assim, estima-se que a demência afete mais de 47 milhões de pessoas em todo o mundo, com $60 \%$ a $80 \%$ dos casos atribuíveis à DA ${ }^{9}$. Nesse sentido, corresponde à forma mais comum de demência, afetando cerca de 25 milhões de pessoas no mundo. Em 2050, acredita-se que 1 entre 85 pessoas no mundo será afetada pela $\mathrm{DA}^{10,11}$. No Brasil, a proporção de pessoas acima de 65 anos com a doença é em torno de 7,7 por 1.000. Na Europa, aproximadamente 4,4\% da população acima de 65 anos têm DA. Já nos Estados Unidos, em torno de 9,7\% das pessoas acima de 70 anos têm a doença. No mundo, aproximadamente 3,9\% das pessoas são afetadas pela demência; na América Latina essa porcentagem corresponde a 4,6\%.
Estudos afirmam que cerca de 5 milhões de novos casos de DA surgem por ano e que o número de casos quase dobra a cada cinco anos nos pacientes acima de 65 anos. A taxa de incidência de DA aumenta quase exponencialmente com o aumento da idade, até os 85 anos de idade ${ }^{10}$.

Alterações nas funções dos neurotransmissores clássicos, neuropeptídeos e fatores de crescimento como acetilcolina (ACh), somatostatina e fator neurotrófico derivado do cérebro são agravantes na DA ${ }^{12-14}$. O sistema neurotransmissor da ACh foi foco de pesquisas no campo da DA por muito tempo, dado que pacientes com DA apresentavam baixos níveis de ACh no cérebro e que baixos níveis são associados a danos cognitivos ${ }^{15}$. Perturbações da função sináptica e da atividade de redes neurais são associadas a níveis elevados da proteína APP e sua acumulação pode eventualmente levar à morte neural ${ }^{16}$. Além da proteína APP, outras proteínas, incluindo diversos receptores, podem estar envolvidas com a doença. A agregação e a disseminação da proteína TAU e a consequente inflamação e neurodegeneração também estão correlacionadas com o declínio cognitivo ${ }^{17}$. As proteínas Sglll e CPE foram identificadas como importantes componentes-chave da via secretora reguladora, pois em pacientes com DA elas se apresentam em baixas quantidades no líquido cefalorraquidiano ${ }^{18,19} \mathrm{e}$ a eliminação da CPE in vivo leva a degeneração neuronal e déficits de memória ${ }^{20,21}$.

Durante vários anos, acreditava-se que a sinalização de GABA não era particularmente afetada na DA, com alguns estudos iniciais demonstrando preservação dos interneurônios GABAérgicos e outros relatando mudanças inconsistentes e frequentemente contraditórias nos níveis de GABA, atividade da enzima GAD e expressão do receptor GABA no cérebro na condição da DA ${ }^{22,23}$. Nesse sentido, o sistema GABAérgico sofre remodelação significativa no cérebro de pacientes com DA, mas é importante reconhecer se isso é consequência da doença em si ou secundário à neurodegeneração ${ }^{24}$. A maioria dos aspectos relacionados ao sistema de sinalização GABA, incluindo os níveis de GABA, correntes de GABA, níveis de expressão e características funcionais dos receptores GABA e transportadores, é afetada na $\mathrm{DA}^{25-28}$.

A expressão da maioria das subunidades do receptor GABA (GABAAR) é alterada de maneira específica no hipocampo de pacientes com DA e deve servir como base para futuros trabalhos que visam compreender os mecanismos complexos subjacentes a essa remodelação, bem como sua 
contribuição para a disfunção cognitiva. Nessa perspectiva, as pesquisas nessa área talvez possam levar à formulação de terapias GABAérgicas inovadoras para a restauração da cognição em pacientes com DA ${ }^{29}$. Adicionalmente, os sistemas excitatórios glutamatérgicos e colinérgicos são severamente afetados na DA, devido à perda significativa de células nesses sistemas e ao rompimento de seus componentes moleculares ${ }^{3}$. Como resultado, o equilíbrio excitatório/inibitório é perturbado no cérebro em condição de DA, o que pode estar relacionado com déficits na memória e na aprendizagem, características da condição. Em um cérebro adulto saudável, a micróglia apresenta morfologia ramificada, porém, quando doenças neurodegenerativas ou lesão neural estão presentes, a micróglia é ativada, atrofiando-se ou apresentando um formato ameboide. Quando ativada, a micróglia pode apresentar funções opostas. Receptores presentes na superfície microglial são responsáveis por detectar mudanças na região proximal à micróglia e controlar a sua ativação ${ }^{30}$.

Nos últimos anos, técnicas modernas permitiram o desenvolvimento de estudos incluindo humanos e animais, abordando questões relevantes em relação às proteínas envolvidas com doenças neurodegenerativas, incluindo a DA. Nessa perspectiva, este artigo tem por finalidade revisar as pesquisas recentes e mais relevantes relacionadas com os receptores neurais que estão associados à DA, a fim de determinar a família de receptores mais estudada, a região do sistema nervoso que contém mais tipos de receptores relacionados com a DA e quais as funções desses receptores que estão predominantemente associadas com a doença neste estudo. Finalmente, o artigo busca determinar os modelos e métodos mais utilizados nas pesquisas sobre o tema.

\section{MÉTODOS}

Por tratar-se de uma revisão sistemática de literatura de natureza descritiva, verificou-se a existência prévia de revisões sistemáticas sobre o tema proposto na Biblioteca Cochrane (The Cochrane Database of Systematic Reviews) e PROSPERO (International Prospective Register of Systematic Reviews). Não foram encontradas revisões relacionadas aos receptores neurais envolvidos na DA (www.crd.york.ac.uk/prospero); os estudos encontrados tratavam do tratamento e diagnóstico da doença. Dessa forma, a pesquisa foi registrada na PROSPERO (ID 141957).

A busca dos estudos primários foi realizada nas bases de dados PubMed/MEDLINE (Public MEDLINE) e Scientific Eletronic Library Online (SciELO), por meio de uma estratégia de busca baseada no objeto de estudo. Para a composição da estratégia de busca, utilizaram-se os termos do MeSH (Medical Subject Headings Terms). Utilizaram-se operadores lógicos de busca (parênteses, trucagem e aspas), além de delimitadores booleanos (AND, OR e NOT). As palavras-chave ("Alzhei- mer receptor" e/ou "Alzheimer disease" e/ou "Neural receptor") foram pesquisadas em inglês e o período da busca foi de janeiro de 2000 a setembro de 2018.

Os critérios de inclusão foram estudos: a) quantitativos, qualitativos ou qualiquantitativos que apresentassem resultados referentes aos receptores neurais envolvidos na DA; b) com dados conclusivos; c) utilizando modelos humanos e/ou animais e/ou cultura celular; d) disponíveis na língua inglesa. Foram critérios de exclusão: normas técnicas, manuais, leis, resoluções, editoriais, cartas, comentários, livros, resumo de anais de congressos e publicações ou receptores duplicados. Ou seja, incluímos na pesquisa apenas artigos científicos escritos em inglês, publicados em revistas indexadas, com alto fator de impacto e recentes (de 2000 a 2018).

A seleção dos estudos se iniciou por meio da análise dos títulos dos artigos identificados a partir da estratégia de busca. Em seguida, foi realizada a análise dos resumos e, por fim, a análise do texto na íntegra dos artigos selecionados nas etapas anteriores. Diante dessa sistemática, os dados extraídos foram: a) identificação da publicação e base de dados consultada; b) receptor analisado e a família à qual pertence; c) local de expressão no sistema nervoso (tecido e/ou célula); d) a função relacionada à DA exercida pelo receptor; e) o ligante ou fármaco atuante; f) o principal achado do artigo analisado; g) o modelo mais utilizado; h) o(s) métodos mais utilizado(s). Para analisar matematicamente as informações acima citadas, em nível de proporção/porcentagem, selecionamos apenas os trabalhos que continham todas essas informações necessárias para as análises, portanto a limitação de estudo refere-se ao número de artigos encontrados, o que poderia afetar em parte a evidência cumulativa. No entanto, a representação dos dados em termos de proporção reduz esse viés.

A avaliação do risco de viés dos estudos individuais foi realizada em nível dos resultados, manualmente; assim, os estudos com viés que poderiam interferir nos resultados foram eliminados. Os dados extraídos foram confirmados durante uma segunda análise e após a organização desses dados, as informações relevantes foram apresentadas de forma descritiva por meio de tabelas e, subsequentemente, discutidas no corpo da revisão. Por fim, as informações de interesse foram compiladas no Excel, o qual forneceu os gráficos e as proporções referentes às variáveis analisadas.

\section{RESULTADOS E DISCUSSÃO}

O método de busca empregado apontou 6.892 artigos, 25 resultaram da pesquisa no banco de dados SciELO e 6.867 foram provenientes do PubMed/MEDLINE. Após a primeira avaliação, 5.234 estudos foram excluídos pela análise dos títulos e resumos, em ambos os casos por não estarem condizentes com a temática e os objetivos desta revisão. 
Após a leitura dos artigos selecionados, 1.003 artigos foram excluídos devido à ausência de dados, enquanto 616 artigos foram excluídos por não atenderem aos critérios de inclusão ou ainda por atenderem aos critérios de exclusão. Ao final, 26 artigos foram incluídos na revisão, sendo todos internacionais (escritos em inglês), disponíveis on-line em texto completo. Após a leitura seletiva dos textos escolhidos, as informações úteis foram extraídas e registradas (Figura 1).

Ao longo dos últimos anos, pesquisas com humanos e animais têm sido desenvolvidas com o objetivo de identificar receptores que então envolvidos na DA, tendo como objetivo uma melhor compreensão a respeito dos mecanismos e aspectos patofisiológicos da doença (Tabelas 1 e 2). Tais receptores, estando ou não associados com a terapêutica na DA, possuem relevância, uma vez que o bloqueio ou ativação deles podem repercutir em melhora ou piora do quadro clínico da doença. Ou seja, tais receptores podem estar envolvidos no prognóstico da DA.

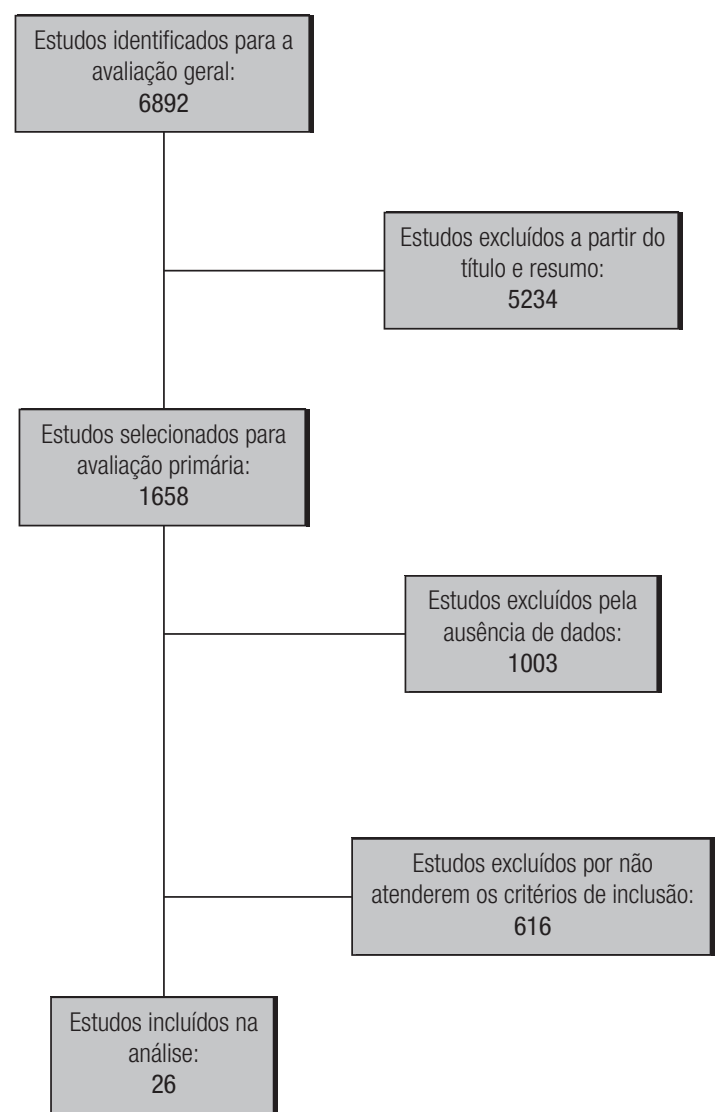

Figura 1. Fluxograma da busca pelos artigos. $\bigcirc$ método de busca empregado apontou 6.892 artigos; 25 resultaram da pesquisa no banco de dados SciELO e 6.867 no PubMed/ MEDLINE. Após a primeira avaliação, 5.234 estudos foram excluídos pela análise dos títulos e resumos, em ambos os casos por não estarem condizentes com a temática e os objetivos desta revisão. Foram excluídos 1.003 artigos devido à ausência de dados e 616 artigos por não atenderem aos critérios de inclusão ou ainda por atenderem aos critérios de exclusão. Ao final, 26 artigos foram incluídos na revisão.
Um grupo de receptores que estão envolvidos com os efeitos neuroprotetores na DA são os receptores da ACh. Agonistas e antagonistas desse receptor nicotínico mostraram desempenhar efeitos positivos na memória. A cotinina e a metilciclonitina são alguns exemplos de ligantes que estiveram associadas com a proteção cerebral, quando testes in vitro e in vivo foram realizados ${ }^{48}$. Outro alvo importante na DA é o receptor de estrogênio $\beta$, que representa uma abordagem terapêutica, e sua ativação por meio de agonistas prolongou a sobrevivência, melhorou a memória de reconhecimento espacial e retardou a progressão da patologia amiloide em um modelo animal de DA. Polimorfismos genéticos do ERß têm sido associados com comprometimento cognitivo e aumento do risco de DA, predominantemente em mulheres ${ }^{50}$.

Em relação aos receptores rianodina (RyR), esses se consistem em uma família de canais iônicos responsáveis pela liberação de cálcio das reservas intracelulares durante a contração muscular. Sabe-se que a homeostase do cálcio está relacionada com a cognição; dessa forma, o RyR pode estar associado com a DA, em especial o RyR 3, encontrado em diversas áreas do sistema nervoso. RyR 1 e RyR 2 também são encontrados no cérebro, embora não estejam predominantemente presentes no sistema nervoso. O RyR pode ser regulado por várias proteínas, íons, bem como modificações redox. É importante ressaltar que os antioxidantes impedem declínio na cognição, despolarização a longo prazo e perda de memória, por meio da inibição da sensibilização do RyR ${ }^{51}$.

Assim como o receptor rianodina, a inibição do receptor GABA também está relacionada com um melhor prognóstico na DA. Por exemplo, o CGP35348 é um antagonista $\mathrm{GABA}_{\mathrm{B}} \mathrm{R}$ e a concentração desse antagonista no hipocampo é um ponto crucial para suprimir ou facilitar a memória ${ }^{33}$. Recentemente, a relação entre receptor RAGE e DA também foi estabelecida; RAGE está envolvido com o transporte da proteína beta-amiloide por meio da barreira hematoencefálica para o parênquima cerebral. As interações entre RAGE e APP causam respostas inflamatórias e estresse oxidativo, além de reduzir o fluxo sanguíneo cerebral. A forma solúvel de RAGE pode suprimir a regulação negativa da via de morte celular e via inflamatória. Além disso, RAGE também inibe a captação de APP e ligantes RAGE, tais como AGE, HMGB1 e S100ß, envolvidos na progressão da doença neurodegenerativa. Adicionalmente, interações RAGE/AGE induzem a cascata de apoptose e inflamação neuronal ${ }^{31}$.

A vitamina D exerce suas ações por meio do receptor da vitamina D (VDR), expresso em diversos tecidos, inclusive no sistema nervoso. Pouco se sabe a respeito da influência da vitamina $D$ e do VDR na DA, no entanto alguns estudos mostram que essa relação é importante. Pesquisas relataram maior prevalência da deficiência de vitamina $D$ em pacientes com DA. Além disso, indivíduos com insuficiência de vitamina D possuíram o dobro do risco de desenvolver DA 
Tabela 1. Pesquisas relacionadas aos receptores neurais envolvidos na DA realizadas em 2018

\begin{tabular}{|c|c|c|c|c|c|}
\hline Artigo e base de dados & Receptor e família & $\begin{array}{c}\text { Expressão no sistema } \\
\text { nervoso } 0^{31}\end{array}$ & Função relacionada à DA & $\begin{array}{l}\text { Ligante ou } \\
\text { fármaco atuante }\end{array}$ & Principal achado do artigo \\
\hline $\begin{array}{l}\text { Oh et al., } 2018^{32} \\
\text { PubMed }\end{array}$ & $\begin{array}{l}\text { Receptor para os } \\
\text { produtos finais de } \\
\text { glicação avançada } \\
\text { (RAGE) } \\
\text { Superfamília das } \\
\text { imunoglobulinas }\end{array}$ & $\begin{array}{l}\text { Micróglia e células } \\
\text { imunes do SNC }\end{array}$ & $\begin{array}{l}\text { Contribui para a morte } \\
\text { celular neuronal relacionada } \\
\text { à inflamação em modelos } \\
\text { de DA. }\end{array}$ & $\begin{array}{l}\text { HMGB1, oligômeros } \\
\text { APP, polipeptídeos } \\
\text { S100, calgranulinas e } \\
\text { anfoterinas }\end{array}$ & $\begin{array}{l}0 \text { tratamento com sRAGE e } \\
\text { células-tronco mesenquimais } \\
\text { (MSC) reduziu o número de } \\
\text { células neuronais apoptóticas } \\
\text { e preveniu a morte celular } \\
\text { neuronal mais do que } 0 \\
\text { tratamento isolado com MSC. }\end{array}$ \\
\hline $\begin{array}{l}\text { Almasi et al., } 2018^{33} \\
\text { PubMed }\end{array}$ & $\begin{array}{l}\text { Receptor do ácido } \\
\text { aminobutírico } \\
\left(G_{\left.A B A_{B} R\right)}\right. \\
\text { Receptor } \\
\text { ionotrópico }\end{array}$ & $\begin{array}{l}\text { Córtex cerebral } \\
\text { (giro denteado), } \\
\text { hipocampo, cerebelo } \\
\text { e núcleo caudado }\end{array}$ & $\begin{array}{l}\text { Regulação da aprendizagem, } \\
\text { memória e função cognitiva. } \\
\text { Inibe a adenilil ciclase, a } \\
\text { cascata AMPc e a liberação de } \\
\text { GABA. Controla a liberação de } \\
\text { glutamato. }\end{array}$ & CGP35348 & $\begin{array}{l}\text { Antagonistas do receptor } \\
\text { GABA }_{B} \text { podem ser um possível } \\
\text { agente terapêutico contra } \\
\text { a progressão da deficiência } \\
\text { aguda de memória induzida } \\
\text { pela toxicidade APP. }\end{array}$ \\
\hline $\begin{array}{l}\text { Chakrabarty et al., } 2018^{34} \\
\text { PubMed }\end{array}$ & $\begin{array}{l}\text { Receptor do tipo Toll } \\
5 \text { (TLR5) } \\
\text { Família de } \\
\text { receptores do tipo } \\
\text { Toll }\end{array}$ & Córtex cerebral & $\begin{array}{l}0 \text { TLR5 liga-se aos oligômeros } \\
\text { e fibrilas APP com alta } \\
\text { afinidade, formando } \\
\text { complexos que bloqueiam a } \\
\text { toxicidade de APP. }\end{array}$ & Flagelina & $\begin{array}{l}\text { Dados biológicos } \\
\text { relacionados ao TLR5 } \\
\text { sugerem esse receptor } \\
\text { como um potencial agente } \\
\text { na terapia da DA, uma } \\
\text { vez que o TLR5 interage } \\
\text { diretamente com a proteína } \\
\text { APP, atenuando os níveis de } \\
\text { APP in vivo. }\end{array}$ \\
\hline $\begin{array}{l}\text { Guedes et al., } 2018^{35} \\
\text { PubMed }\end{array}$ & $\begin{array}{l}\text { Receptor de } \\
\text { quimiocinas C-C tipo } \\
2 \text { (CCR2) } \\
\text { Família de } \\
\text { receptores da } \\
\text { quimiocina }\end{array}$ & $\begin{array}{l}\text { Córtex cerebral, } \\
\text { hipocampo, cerebelo, } \\
\text { núcleo caudado } \\
\text { (micróglia) }\end{array}$ & $\begin{array}{l}\text { 0 CCR2 promove } 0 \\
\text { recrutamento de monócitos } \\
\text { da medula óssea para } 0 \\
\text { sangue, depois do sangue } \\
\text { para o espaço perivascular, } \\
\text { depois para locais de depósito } \\
\text { de APP no parênquima, onde } \\
\text { essas células podem fagocitar } \\
\text { proteínas APP. }\end{array}$ & Quimiocinas C-C tipo 2 & $\begin{array}{l}\text { Monócitos CCR2 + podem } \\
\text { atuar como protetores na DA. }\end{array}$ \\
\hline $\begin{array}{l}\text { Guedes et al., } 2018^{35} \\
\text { PubMed }\end{array}$ & $\begin{array}{l}\text { Receptor de } \\
\text { quimiocina CX3C } 1 \\
\text { (CX3CR1) } \\
\text { Família de } \\
\text { receptores da } \\
\text { quimiocina }\end{array}$ & $\begin{array}{l}\text { Córtex cerebral, } \\
\text { hipocampo, núcleo } \\
\text { caudado (micróglia) }\end{array}$ & $\begin{array}{l}0 \text { CX3CR1 mantém a } \\
\text { homeostase microglial, } \\
\text { sendo essencial para a } \\
\text { função da micróglia no } \\
\text { suporte sináptico. } 0 \text { CX3CR1 } \\
\text { exerce funções cognitivas } \\
\text { dependentes de IL-1ß. }\end{array}$ & Quimiocina CX3CL1 & $\begin{array}{l}\text { É possível que o CX3CR1 } \\
\text { esteja envolvido na morte } \\
\text { de neurônios com depósitos } \\
\text { intracelulares da proteína TAU } \\
\text { e a subsequente liberação de } \\
\text { TAU. Estudos adicionais com } \\
\text { modelos de AD que exibem } \\
\text { ambas as patologias APP e TAU } \\
\text { são necessários para esclarecer } \\
\text { o papel do CX3CR1 na DA. }\end{array}$ \\
\hline $\begin{array}{l}\text { Kootar et al., } 2018^{36} \\
\text { PubMed }\end{array}$ & $\begin{array}{l}\text { Receptor de } \\
\text { glicocorticoides } \\
\text { (GCRs) } \\
\text { Família de } \\
\text { receptores de } \\
\text { glicocorticoides }\end{array}$ & $\begin{array}{l}\text { Córtex cerebral, } \\
\text { hipocampo, cerebelo, } \\
\text { núcleo caudado }\end{array}$ & $\begin{array}{l}\text { GRs podem participar da } \\
\text { geração e atividade da } \\
\text { proteína APP no cérebro. }\end{array}$ & $\begin{array}{l}\text { Agonistas: } \\
\text { dexametasona e } \\
\text { outros corticosteroides } \\
\text { Antagonistas: } \\
\text { mifepristona e } \\
\text { cetoconazol. }\end{array}$ & $\begin{array}{l}\text { Há um cross-talk entre a } \\
\text { proteína APP e GRs nas } \\
\text { sinapses excitatórias do } \\
\text { hipocampo, que podem } \\
\text { contribuir para a atividade } \\
\text { cerebral anormal durante a } \\
\text { patogênese da DA. }\end{array}$ \\
\hline $\begin{array}{l}\text { Wang et al., } 2018^{37} \\
\text { PubMed }\end{array}$ & $\begin{array}{l}\text { Receptor de } \\
\text { lipoproteína de } \\
\text { baixa densidade } \\
\text { oxidada semelhante } \\
\text { à lectina } 1 \text { (0LR1) } \\
\text { Superfamília lectina } \\
\text { tipo C }\end{array}$ & Córtex cerebral & $\begin{array}{l}\text { Desempenha papel no } \\
\text { metabolismo lipídico. Medeia } \\
\text { a captação e internalização da } \\
\text { lipoproteína oxidada de baixa } \\
\text { densidade (oxLDL), que pode } \\
\text { estar envolvida na DA. }\end{array}$ & LDL oxidado & $\begin{array}{l}\text { Os SNPs (rs1050283, } \\
\text { rs1050286, rs17808009) } \\
\text { localizados na 3'UTR da 0LR1 } \\
\text { podem não estar envolvidos } \\
\text { no mecanismo da DA na } \\
\text { população chinesa Han. }\end{array}$ \\
\hline $\begin{array}{l}\text { Chen et al., } 2018^{38} \\
\text { PubMed }\end{array}$ & $\begin{array}{l}\text { Receptor acoplado } \\
\text { à proteína G } 40 \\
\text { (GPR40) } \\
\text { Família de } \\
\text { receptores } \\
\text { acoplados à } \\
\text { proteína G }\end{array}$ & Córtex cerebral & $\begin{array}{l}\text { Amplifica a secreção de } \\
\text { insulina dependente de } \\
\text { glicose sem o risco de } \\
\text { hipoglicemia. Em pacientes } \\
\text { com DA, há uma diminuição } \\
\text { no sinal da insulina } \\
\text { intracerebral e uma mudança } \\
\text { no nível de insulina do líquido } \\
\text { cefalorraquidiano. }\end{array}$ & Ácidos graxos & $\begin{array}{l}0 \text { agonista de GPR40 pode } \\
\text { promover a neurogênese adulta } \\
\text { e inibir a apoptose neuronal. } \\
\text { Também desempenha um } \\
\text { papel vital na proteção dos } \\
\text { nervos e na diminuição do dano } \\
\text { cerebral. No entanto, ainda } \\
\text { existem alguns problemas a } \\
\text { serem resolvidos. }\end{array}$ \\
\hline
\end{tabular}




\begin{tabular}{|c|c|c|c|c|c|}
\hline Artigo e base de dados & Receptor e família & $\begin{array}{c}\text { Expressão no sistema } \\
\text { nervoso }{ }^{31}\end{array}$ & Função relacionada à DA & $\begin{array}{c}\text { Ligante ou } \\
\text { fármaco atuante }\end{array}$ & Principal achado do artigo \\
\hline $\begin{array}{l}\text { Deming et al., } 2018^{39} \\
\text { PubMed }\end{array}$ & $\begin{array}{l}\text { Receptor } \\
\text { desencadeado } \\
\text { expresso em células } \\
\text { mieloides } 2 \\
\text { (TREM2) } \\
\text { Superfamília das } \\
\text { imunoglobulinas }\end{array}$ & $\begin{array}{l}\text { Córtex cerebral, } \\
\text { hipocampo, núcleo } \\
\text { caudado e cerebelo } \\
\text { (micróglia) }\end{array}$ & $\begin{array}{l}0 \text { TREM2 parece ser necessário } \\
\text { para a sobrevivência } \\
\text { microglial, resposta } \\
\text { inflamatória e microglial, } \\
\text { fagocitose induzida, } \\
\text { maturação de células } \\
\text { dendríticas e osteoclastos, } \\
\text { entre outras. }\end{array}$ & $\begin{array}{l}\text { Fosfolipídios, } \\
\text { ácidos nucleicos, } \\
\text { proteoglicanos, APOE, } \\
\text { HSP60 e clusterina }\end{array}$ & $\begin{array}{l}0 \text { TREM2 tem sido } \\
\text { fortemente associado à DA } \\
\text { e desempenha um papel } \\
\text { fundamental na imunidade } \\
\text { inata; no entanto, os } \\
\text { mecanismos exatos não são } \\
\text { claros. }\end{array}$ \\
\hline $\begin{array}{l}\text { Khoury et al., } 2018^{40} \\
\text { PubMed }\end{array}$ & $\begin{array}{l}\text { Receptor } \\
\text { 5-hidroxitriptamina } \\
6 \text { (5 HTR6) } \\
\text { Família de } \\
\text { receptores } \\
\text { acoplados à } \\
\text { proteína G }\end{array}$ & $\begin{array}{l}\text { Córtex cerebral, } \\
\text { hipotálamo, } \\
\text { hipocampo, núcleo } \\
\text { caudado e glândula } \\
\text { pituitária }\end{array}$ & $\begin{array}{l}\text { Controla a migração } \\
\text { dos neurônios piramidais } \\
\text { durante a corticogênese. É um } \\
\text { ativador da sinalização TOR. } \\
\text { Parece regular a atividade } \\
\text { gabaérgica, glutamatérgica } \\
\text { e colinérgica. Está envolvido } \\
\text { na cognição, ansiedade, } \\
\text { memória, estado afetivo, } \\
\text { entre outros. }\end{array}$ & $\begin{array}{l}\text { Antagonistas: } \\
\text { idalopirdina, } \\
\text { intepirdina e SUVN- } \\
\text { 502. Agonistas: } \\
\text { serotonina, WAY- } \\
\text { 181,187 e WAY-208,466 }\end{array}$ & $\begin{array}{l}\text { Os agonistas do receptor } \\
\text { 5-HT6 mostraram repercurtir } \\
\text { em propriedades cognitivas } \\
\text { melhoradas. }\end{array}$ \\
\hline $\begin{array}{l}\text { Takkinen et al., } 2018^{41} \\
\text { PubMed }\end{array}$ & $\begin{array}{l}\text { Receptor } \\
\text { canabinoide } 1 \\
\text { (CB1R) } \\
\text { Família de } \\
\text { receptores } \\
\text { acoplados à } \\
\text { proteína G }\end{array}$ & $\begin{array}{l}\text { Córtex cerebral, } \\
\text { hipocampo, núcleo } \\
\text { caudado e cerebelo } \\
\text { (micróglia) }\end{array}$ & $\begin{array}{l}\text { Diminui a concentração } \\
\text { intracelular de AMPc, inibindo } \\
\text { a enzima adenilato ciclase e } \\
\text { aumentando a concentração } \\
\text { de proteína quinase ativada } \\
\text { por mitógeno. Atua como um } \\
\text { neuromodulador para inibir } \\
\text { a liberação de glutamato e } \\
\text { GABA. }\end{array}$ & $\begin{array}{l}\text { Endocanabinoides, } \\
\text { anandamida, } \\
\text { 2-araquidonoilglicerol, } \\
\text { canabinoides vegetais } \\
\text { e análogos sintéticos } \\
\text { de THC }\end{array}$ & $\begin{array}{l}\text { [18F] FMPEP-d2 é uma } \\
\text { ferramenta promissora para } \\
\text { pesquisa da DA em termos de } \\
\text { disponibilidade de CB1R. Essa } \\
\text { descoberta pode facilitar } 0 \\
\text { desenvolvimento de novas } \\
\text { abordagens terapêuticas } \\
\text { baseadas na regulação } \\
\text { endocanabinoide. }\end{array}$ \\
\hline $\begin{array}{l}\text { Barrera et al., } 2018^{42} \\
\text { PubMed }\end{array}$ & $\begin{array}{l}\text { Receptor-p ativado } \\
\text { por proliferador } \\
\text { de peroxissoma } \\
\text { (PPARy) } \\
\text { Família de } \\
\text { receptores de } \\
\text { transcrição nuclear }\end{array}$ & $\begin{array}{l}\text { Córtex cerebral, } \\
\text { hipocampo, núcleo } \\
\text { caudado e cerebelo }\end{array}$ & $\begin{array}{l}\text { Participa de vias envolvidas } \\
\text { no metabolismo lipídico e na } \\
\text { resposta imune, que foram } \\
\text { implicadas na etiologia da DA. }\end{array}$ & $\begin{array}{l}\text { Ácidos graxos, } \\
\text { prostaglandinas e } \\
\text { leucotrienos }\end{array}$ & $\begin{array}{l}0 \text { PPARy pode atuar como } \\
\text { um regulador mestre da } \\
\text { transcrição de vários genes } \\
\text { envolvidos na patogênese } \\
\text { da DA. }\end{array}$ \\
\hline $\begin{array}{l}\text { Mirzaei et al., } 2018^{43} \\
\text { PubMed }\end{array}$ & $\begin{array}{l}\text { Receptor do tipo } \\
\text { NOD contendo um } \\
\text { domínio de pirina } \\
\text { do tipo } 3 \text { (NLRP3) } \\
\text { Família de } \\
\text { receptores do tipo } \\
\text { NOD (inflamossoma) }\end{array}$ & $\begin{array}{l}\text { Córtex cerebral } \\
\text { e hipocampo } \\
\text { (micróglia) }\end{array}$ & $\begin{array}{l}\text { A ativação do NLRP3 leva } \\
\text { à produção de pré-IL-1ß e } \\
\text { pré-IL-18, e suas conversões } \\
\text { para as formas ativas, que } \\
\text { desempenham papel na } \\
\text { resposta inflamatória no } \\
\text { sistema nervoso central e na } \\
\text { patogênese da DA. }\end{array}$ & $\begin{array}{l}\text { Componentes de } \\
\text { peptideoglicano }\end{array}$ & $\begin{array}{l}0 \text { óleo de coco virgem } \\
\text { melhorou a saúde do } \\
\text { hipocampo, memória e } \\
\text { aprendizagem em modelos } \\
\text { de ratos com Alzheimer ao } \\
\text { inibir o NLRP3 e reduzir } 0 \\
\text { estresse oxidativo. }\end{array}$ \\
\hline $\begin{array}{l}\text { Yeo et al., } 2018^{44} \\
\text { PubMed }\end{array}$ & $\begin{array}{l}\text { Receptor do tipo Toll } \\
4 \text { (TLR4) } \\
\text { Família de } \\
\text { receptores do tipo } \\
\text { Toll }\end{array}$ & Córtex cerebral & $\begin{array}{l}0 \text { TLR4 induz a sinalização } \\
\text { de CREB, que regula a } \\
\text { sobrevivência precoce dos } \\
\text { neurônios, a expressão gênica } \\
\text { neuronal e a neurogênese } \\
\text { na zona subventricular de } \\
\text { adultos. }\end{array}$ & Lipopolissacarídeos & $\begin{array}{l}\text { Em conjunto, esses estudos } \\
\text { indicaram que o PRDX6 inibe } \\
\text { a neurogênese das células- } \\
\text { tronco neurais por meio da } \\
\text { regulação negativa da via de } \\
\text { sinalização de TLR4 mediada } \\
\text { por WDFY1 e sugerem } \\
\text { que o efeito inibitório do } \\
\text { PRDX6 na neurogênese } \\
\text { desempenha um papel no } \\
\text { desenvolvimento de doenças } \\
\text { neurodegenerativas. }\end{array}$ \\
\hline $\begin{array}{l}\text { Valencia et al., } 2018^{45} \\
\text { PubMed }\end{array}$ & $\begin{array}{l}\text { Receptor sigma } 1 \\
\text { (o1R) } \\
\text { Proteína chaperona }\end{array}$ & $\begin{array}{l}\text { Córtex cerebral, } \\
\text { hipocampo, núcleo } \\
\text { caudado e cerebelo }\end{array}$ & $\begin{array}{l}0 \sigma 1 R \text { pode estar envolvido } \\
\text { na proteção de uma linhagem } \\
\text { celular neuronal contra } 0 \\
\text { estresse oxidativo e com } \\
\text { a maturação das células- } \\
\text { tronco neurais, o que poderia } \\
\text { contribuir para a reparação } \\
\text { dos tecidos neuronais. }\end{array}$ & $\begin{array}{l}\text { Donepezila- } \\
\text { flavonoides híbridos } \\
\text { (DFHs) }\end{array}$ & $\begin{array}{l}0 \text { o1R, juntamente com seu } \\
\text { ligante DFH, pode exercer } \\
\text { um papel na inibição de } \\
\text { enzimas envolvidas na DA, } \\
\text { como a acetilcolinesterase, } \\
\text { 5-lipoxigenase e monoamina } \\
\text { oxidase. }\end{array}$ \\
\hline
\end{tabular}

Dados extraídos dos artigos publicados em 2018: Referência (autor e ano), base de dados consultada, nome do receptor envolvido na DA e família à qual pertence, região na qual o receptor se expressa, função do receptor que está relacionada com a DA, ligante ou fármaco que atua no receptor e o principal achado do artigo. 
Tabela 2. Pesquisas relacionadas aos receptores neurais envolvidos na DA realizadas entre 2012 e 2017

\begin{tabular}{|c|c|c|c|c|c|}
\hline $\begin{array}{l}\text { Artigo e base de } \\
\text { dados }\end{array}$ & Receptor e familia & $\begin{array}{l}\text { Expressão no sistema } \\
\text { nervoso } 0^{31}\end{array}$ & Função relacionada à DA & $\begin{array}{l}\text { Ligante ou } \\
\text { fármaco atuante }\end{array}$ & Principal achado do artigo \\
\hline $\begin{array}{l}\text { Cramer et al., } \\
2012^{16} \\
\text { PubMed }\end{array}$ & $\begin{array}{l}\text { Receptor X Retinoide (RXR) } \\
\text { Família de receptores de } \\
\text { transcrição nuclear }\end{array}$ & $\begin{array}{l}\text { Córtex cerebral, } \\
\text { hipocampo, núcleo } \\
\text { caudado e cerebelo }\end{array}$ & $\begin{array}{l}\text { A ativação do RXR estimula } \\
\text { mecanismos fisiológicos de } \\
\text { eliminaçã̃o de APP, resultando } \\
\text { na reversão de déficits induzidos } \\
\text { por APP. }\end{array}$ & Bexaroteno & $\begin{array}{l}0 \text { bexaroteno estimulou a rápida reversão } \\
\text { de déficits cognitivos, sociais e olfativos e } \\
\text { melhorou a função do circuito neural. }\end{array}$ \\
\hline $\begin{array}{l}\text { Wang et al., } \\
2012^{46} \\
\text { PubMed }\end{array}$ & $\begin{array}{l}\text { Receptor da vitamina D (VDR) } \\
\text { Família de receptores de } \\
\text { transcrição nuclear }\end{array}$ & $\begin{array}{l}\text { Hipotálamo e } \\
\text { substância negra }\end{array}$ & $\begin{array}{l}0 \text { VDR medeia as ações biológicas } \\
\text { da vitamina D. A vitamina D } \\
\text { desempenha um papel ativo no } \\
\text { sistema nervoso. O VDR interage } \\
\text { com o SMAD3, conhecido por } \\
\text { regular a transcrição da proteína } \\
\text { APP por meio da sinalização TGF } \beta \text {. }\end{array}$ & Vitamina D & $\begin{array}{l}\text { Primeiros a mostrar que o VDR e a vitamina D } \\
\text { suprimem a atividade do promotor do gene } \\
\text { APP, sugerindo que APP é um novo gene-alvo } \\
\text { para a sinalização de VDR, fornecendo um } \\
\text { mecanismo molecular para a associação } \\
\text { genética entre o VDR e o risco de DA tardio. }\end{array}$ \\
\hline $\begin{array}{l}\text { Plá et al., 2012 } \\
\text { PubMed }\end{array}$ & $\begin{array}{l}\text { Receptores de triagem secretora } \\
\text { carboxipeptidase E (CPE) e } \\
\text { secretogranina III (SgIIII) } \\
\text { CPE: família das enzimas e } \\
\text { proteínas plasmáticas } \\
\text { Sglll: família de proteínas } \\
\text { secretoras neuroendócrinas }\end{array}$ & $\begin{array}{l}\text { Córtex cerebral, } \\
\text { hipocampoe } \\
\text { cerebelo }\end{array}$ & $\begin{array}{l}\text { Essenciais no processo de } \\
\text { direcionamento de neuropeptídeos } \\
\text { e neurotrofinas, podendo participar } \\
\text { na progressão patológica da DA. }\end{array}$ & $\begin{array}{l}\text { CPE: proteínas das vias } \\
\text { secretoras reguladas, } \\
\text { incluindo pró-hormônios } \\
\text { Sglll: graninas }\end{array}$ & $\begin{array}{l}\text { Foi relatada pela primeira vez a distribuição } \\
\text { específica de CPE e Sglll em células neuronais } \\
\text { e gliais no cérebro humano saudável. Além } \\
\text { disso, foi demonstrada uma acumulação } \\
\text { desses receptores de triagem em placas senis } \\
\text { de pacientes com DA e em camundongos. }\end{array}$ \\
\hline $\begin{array}{l}\text { Lombardo e } \\
\text { Maskos, } 2015^{48} \\
\text { PubMed }\end{array}$ & $\begin{array}{l}\text { Receptores de } \\
\text { acetilcolina (AChR) } \\
\text { Receptores nicotínicos }\end{array}$ & $\begin{array}{l}\text { Córtex } \\
\text { cerebral }\end{array}$ & Interage com a proteína APP. & $\begin{array}{l}\text { Cotinina, nicotina e seus } \\
\text { análogos }\end{array}$ & $\begin{array}{l}0 \text { uso de diferentes agonistas a } 7 \text { para } n A C h R \\
\text { é uma abordagem promissora que pode ser } \\
\text { utilizada em terapia na } A D \text {. }\end{array}$ \\
\hline $\begin{array}{l}\text { Konishi et al., } \\
2014^{49} \\
\text { PubMed }\end{array}$ & $\begin{array}{l}\text { Receptor alfa da família } \\
\text { GDNF (GFRa) } \\
\text { Receptor de superfície } \\
\text { celular ligado ao } \\
\text { glicosilfosfatidilinositol (GPI) }\end{array}$ & $\begin{array}{l}\text { Córtex cerebral, } \\
\text { hipocampo, núcleo } \\
\text { caudado e cerebelo }\end{array}$ & $\begin{array}{l}\text { Pode exercer efeitos na sobrevida } \\
\text { neuronal em neurônios afetados } \\
\text { pela DA. }\end{array}$ & $\begin{array}{l}\text { Ligante do GFRa: GDNF } \\
\text { Ligante do GFRa2: NRTN } \\
\text { Ligante do GFRa3: ARTN } \\
\text { Ligante do GFRa4: PSPN }\end{array}$ & $\begin{array}{l}\text { Os resultados sugerem que, em neurônios } \\
\text { afetados pela DA, os defeitos específicos } \\
\text { no GFRa1 podem estar associados à } \\
\text { neurotransmissão glutamatérgica. Essa } \\
\text { observação pode auxiliar no desenvolvimento } \\
\text { de estratégias terapêuticas potenciais para } \\
\text { a DA por meio da regulação positiva da } \\
\text { expressão do GFRa1. }\end{array}$ \\
\hline $\begin{array}{l}\text { Zhao et al., } \\
2015^{50} \\
\text { PubMed }\end{array}$ & $\begin{array}{l}\text { Receptor de estrogênio } \beta \text { (ERß) } \\
\text { Família de receptores de } \\
\text { transcrição nuclear }\end{array}$ & $\begin{array}{l}\text { Hipocampo, córtex } \\
\text { cerebral e tálamo }\end{array}$ & $\begin{array}{l}\text { Desempenha papéis fundamentais } \\
\text { em diversas funções cerebrais, } \\
\text { do desenvolvimento ao } \\
\text { envelhecimento. }\end{array}$ & $\begin{array}{l}\text { Fitoestrógeno seletivo } \\
\text { para ERß, SARM e MF101 }\end{array}$ & $\begin{array}{l}\text { Os polimorfismos do ER } \beta \text { têm sido associados } \\
\text { ao envelhecimento cerebral acelerado e ao } \\
\text { aumento do risco para o desenvolvimento da } \\
\text { DA predominantemente em mulheres. }\end{array}$ \\
\hline $\begin{array}{l}\text { Camara et al., } \\
2016^{51} \\
\text { PubMed }\end{array}$ & $\begin{array}{l}\text { Receptor rianodina } 3 \text { (RyR3) } \\
\text { Canais de cálcio } \\
\text { intracelulares }\end{array}$ & $\begin{array}{l}\text { Hipocampo, } \\
\text { tálamo, núcleo } \\
\text { estriado, cerebelo, } \\
\text { glândula pituitária }\end{array}$ & $\begin{array}{l}\text { Efeitos negativos relacionados } \\
\text { com a transmissão e a plasticidade } \\
\text { sináptica na DA. }\end{array}$ & $\begin{array}{l}\text { Rianodina e } \\
\text { dantroleno }\end{array}$ & $\begin{array}{l}0 \text { RyR está associado à perda de memória e } \\
\text { ao declínio da cognição relacionada com a } \\
\text { idade. A vitamina D indiretamente previne a } \\
\text { sensibilização do RyR }\end{array}$ \\
\hline $\begin{array}{l}\text { Chiarini et al., } \\
2016^{52} \\
\text { PubMed }\end{array}$ & $\begin{array}{l}\text { Receptor sensível ao cálcio } \\
\text { (CaSR) } \\
\text { Família C de receptores } \\
\text { acoplados à proteína G }\end{array}$ & Hipocampo & $\begin{array}{l}\text { Papel na degeneração dos } \\
\text { neurônios hipocampais. Proteína } \\
\text { APP foi capaz de elevar o cálcio } \\
\text { intracelular, abrindo canais } \\
\text { catiônicos não seletivos e } \\
\text { permeáveis ao cálcio em neurônios } \\
\text { do hipocampo. }\end{array}$ & $\begin{array}{l}\text { Cinacalcete e } \\
\text { etelcalcetide }\end{array}$ & $\begin{array}{l}\text { Em estágios iniciais sintomáticos da } \\
\text { DA, os calcilíticos poderiam prevenir ou } \\
\text { terminar a propagação da DA e preservar } \\
\text { a viabilidade dos neurônios humanos e, } \\
\text { consequentemente, as habilidades cognitivas } \\
\text { dos pacientes. }\end{array}$ \\
\hline $\begin{array}{l}\text { Waqar e Batool, } \\
2017^{53} \\
\text { SciELO }\end{array}$ & $\begin{array}{l}\text { Receptores de N-metil-D- } \\
\text { aspartato (NMDAR) } \\
\text { Receptor ionotrópico }\end{array}$ & $\begin{array}{l}\text { Cerebelo, } \\
\text { hipocampo, córtex } \\
\text { cerebral, núcleo } \\
\text { caudado }\end{array}$ & $\begin{array}{l}\text { Participa do desenvolvimento do } \\
\text { sistema nervoso central e está } \\
\text { envolvido na plasticidade sináptica, } \\
\text { essencial na aprendizagem e } \\
\text { memória. }\end{array}$ & Conantokina & $\begin{array}{l}\text { A conantokina pode atuar como antagonista } \\
\text { dos receptores NMDA e desempenhar um } \\
\text { papel importante na compreensão da } \\
\text { importância da inibição dos receptores NMDA } \\
\text { no tratamento da DA. }\end{array}$ \\
\hline $\begin{array}{l}\text { Oliveira et al., } \\
2017^{54} \\
\text { SciEL0 }\end{array}$ & $\begin{array}{l}\text { Receptor de lipoproteína de } \\
\text { baixa densidade (LDLR) } \\
\text { Família dos receptores de } \\
\text { lipoproteínas }\end{array}$ & $\begin{array}{l}\text { Córtex cerebral, } \\
\text { núcleo caudado } \\
\text { e cerebelo (em } \\
\text { todas as células } \\
\text { nucleadas) }\end{array}$ & $\begin{array}{l}\text { Medeia } 0 \text { aumento na expressão } \\
\text { astrocítária de APOE induzida pela } \\
\text { proteína APP. }\end{array}$ & LDL & $\begin{array}{l}\text { Embora os sintomas neuropsiquiátricos } \\
\text { não tenham sido previamente estudados } \\
\text { em associação com as variantes do LDLR, } \\
\text { os genótipos LDLR associados com a } \\
\text { neuropatologia da DA podem levar ao } \\
\text { aparecimento da demência. }\end{array}$ \\
\hline $\begin{array}{l}\text { Oliveira et al., } \\
2017^{54} \\
\text { SciELO }\end{array}$ & $\begin{array}{l}\text { Receptor nuclear } X \text { do fígado } \beta \\
\text { (LXR- } \beta \text { ) } \\
\text { Família de receptores de } \\
\text { transcrição nuclear }\end{array}$ & Córtex cerebral & $\begin{array}{l}\text { Regulador da homeostase } \\
\text { do colesterol, controlando a } \\
\text { amiloidogênese e modulando a } \\
\text { inibição da angiotensina II. }\end{array}$ & $\begin{array}{l}\text { Derivados oxigenados } \\
\text { do colesterol, como } \\
\text { hidroxicolesterois e ácido } \\
\text { colestenoico. Agonistas } \\
\text { LXR sintéticos: T0901317 } \\
\text { e GW3965. }\end{array}$ & $\begin{array}{l}\text { Entre todos os polimorfismos do gene LXR- } \beta \\
\text { (NR1H2), o alelo T do rs2695121 é o mais } \\
\text { significativo para o risco de DA, embora não } \\
\text { tenha sido previamente associado a sintomas } \\
\text { comportamentais. }\end{array}$ \\
\hline
\end{tabular}


comparados a indivíduos com concentrações suficientes de vitamina D. Descobriu-se que a deficiência de vitamina D está associada ao comprometimento cognitivo, tanto em pacientes com DA quanto na população em geral ${ }^{46}$. O receptor da vitamina $D$ interage com o receptor retinoide $X$ (RXR) para que a vitamina D exerça suas ações. A ativação do RXR é capaz de estimular os processos fisiológicos normais por meio dos quais a APP é eliminada do cérebro, mostrando a participação de um componente genético envolvido com o metabolismo da vitamina D na etiologia da DA. Assim, agonistas do RXR podem ser úteis no tratamento da DA e de suas fases antecedentes ${ }^{16}$.

Os sintomas cognitivos associados a déficits na aprendizagem e na memória têm sido atribuídos a distúrbios na neurotransmissão glutaminérgica. A estimulação excessiva dos neurônios pelo neurotransmissor de glutamato causa excitotoxicidade e resulta em danos e morte de neurônios. Dessa forma, o bloqueio da neurotransmissão glutaminérgica mediada por receptores NMDA pode aliviar a excitotoxicidade e prevenir novos danos aos neurônios. Portanto, os antagonistas de NMDAR surgiram como potenciais compostos para pacientes com DA uma vez que o receptor em si tem muitas subunidades e suas variantes têm inúmeras funções cerebrais. Vale resaltar ainda que a subunidade NMDA do subtipo de receptor 2B (NR2B) é o principal receptor do neurotransmissor excitatório no cérebro de mamíferos ${ }^{53}$.

Em relação ao receptor $L D L$, alguns genótipos têm sido relacionados com um maior ou menor risco de demência e DA. Embora os sintomas neuropsiquiátricos não tenham sido previamente estudados em associação com as variantes do LDLR, genótipos associados com a atenuação da neuropatologia da DA poderiam levar ao aparecimento tardio de demência ${ }^{54}$. Os receptores nucleares $X$ do fígado (LXRs) são os principais reguladores da homeostase do colesterol e da inflamação no SNC. O cérebro, que contém grande quantidade do colesterol total do corpo (em torno de $25 \%)$, requer um metabolismo complexo e delicadamente balanceado de colesterol para manter a função neuronal. A desregulação do metabolismo do colesterol tem sido implicada em várias doenças neurodegenerativas, incluindo a DA. Devido às suas atividades anti-inflamatórias, os LXRs desempenham importâcia crucial na função do SNC. Embora o agonismo dos LXRs exerça um potencial terapêutico em doenças de ordem neurológica, o direcionamento do LXR nessas patologias permanece problemático. A recente descoberta de derivados do colesterol que funcionam como agonistas LXR mostrou novos papéis para os LXRs na neurogênese do mesencéfalo. A elucidação do repertório de ligandos endógenos de LXRs vai melhorar a compreensão de como esse receptor regula o metabolismo lipídico no SNC 55 .

Os receptores do tipo Toll (TLRs) são receptores do sistema imune inato que são ativados por patógenos (PAMP) ou padrões moleculares associados a danos (DAMPs). Os TLRs estão associados à lesão neuronal em condições inflamatórias crônicas, mas também à recuperação funcional após lesão nervosa. Os agregados amiloides da DA parecem ser um tipo de DAMP, podendo interagir e ativar receptores de reconhecimento padrões. Duas ações dos TLRs (ligação ao ligante e sinalização imune) podem ter efeitos opostos na patologia da $\mathrm{DA}^{34}$.

Outra molécula estudada na DA é o receptor da quimiocina CX3C1 (CX3CR1). Esse receptor é altamente expresso na micróglia e os camundongos knock-in CX3CR1-GFP (nos quais o GFP substituiu um alelo CX3CR1) foram usados para estudar, in vivo, o papel da micróglia na DA e em outras doenças cerebrais. Em condições fisiológicas, o término da função de CX3CR1 afeta as funções cognitivas de maneira dependente de IL-1 $\beta$ e exacerba a inflamação induzida por LPS, sugerindo que CX3CR1 mantém a homeostase microglial, sendo essencial para as sinapses nervosas. Nesse contexto, a desregulação do eixo CX3CL1/CX3CR1 em modelos camundongos de DA pode desempenhar efeitos neuroprotetores e neurotóxicos dependendo do modelo de camundongo usado.

Ainda em relação aos receptores de quimiocina, o receptor de CCL2 (CCR2) também foi associado com a DA. Em camundongos, a deficiência de CCR2 acelerou a progressão precoce da doença, prejudicando o acúmulo de fagócitos mononucleares. Camundongos APP-CCR2-/- exibiram maiores níveis de proteínas APP com menor recrutamento de células CD11b + no cérebro. É importante ressaltar que esses camundongos apresentaram mortalidade aumentada em um modo dependente da dosagem do gene CCR2. Estudos subsequentes mostraram que a redução de proteínas APP se deveu à falta de acúmulo de monócitos nos espaços perivasculares e possivelmente à sua infiltração no parênquima cerebral. Esses achados foram corroborados pelo fato de que a deficiência de CCR2 piorou os déficits de memória e aumentou o os níveis de APP solúvel em camundongos ${ }^{35}$.

Os glicocorticoides atuam via dois receptores: o mineralocorticoide (MR) e os receptores de glicocorticoides (GR). Tanto os pacientes quanto os modelos de camundongos com DA apresentam um eixo hipotálamo-hipófise adrenal desregulado, marcado por uma leve hipercortisolemia, aparente no início da patologia. Assim, no contexto da DA precoce, enquanto os níveis de proteína APP aumentam lentamente no cérebro, a atividade dos GR provavelmente está anormalmente elevada devido ao aumento nos níveis de $\mathrm{GC}^{36}$. Adicionalmente, o cromossomo 12p foi reconhecido como uma região associada à DA. Esse cromossomo inclui genes para o receptor de lipoproteína 1 (LRP1) e para o receptor de lipoproteína de baixa densidade oxidada semelhante à lectina 1 (OLR1). A OLR1, um receptor scavenger classe E, é uma glicoproteína transmembrana. Fatores in vitro, como LDL oxidado, estresse oxidativo, citocinas inflamatórias e estímulos 
pró-aterogênicos in vivo, como diabetes mellitus, hiperlipidemia e hipertensão, podem induzir sua expressão. O aumento nos níveis de LDL oxidado induz a ativação e a disfunção das células endoteliais e a apoptose e prejudica o vasorelaxamento, contribuindo, assim, para o desenvolvimento e a progressão da aterosclerose. De fato, a literatura epidemiológica e clínica tem relatado uma associação entre aterosclerose, fatores de risco vascular e DA. Portanto, é possível que variações no ORL1 possam levar a uma menor eficiência na remoção de LDL oxidado e, assim, ao aumento do peptídeo beta-amiloide, podendo resultar na morte de neurônios ${ }^{37}$.

Há um grande número de ácidos graxos poli-insaturados no sistema nervoso, tal como o ácido docosa-hexaenoico (DHA), um ácido carboxílico do tipo ômega 3. A ligação do DHA no receptor acoplado à proteína G 40 (GPR40) é capaz de exercer efeitos protetores no sistema nervoso. Por exemplo, pode aumentar a plasticidade sináptica, a atividade neuronal e inibir a apoptose dos neurônios. Em resumo, o GPR40 foi considerado um possível alvo na demência diabética tipo $2^{38}$. Em relação ao receptor desencadeado expresso em células mieloides 2 (TREM2), é relevante compreender a respeito da teraupêutica direcionada a esse receptor, uma vez que ele desempenha papel na DA. TREM2 pode estar relacionado à ativação microglial, patologia mediada pela proteína amiloide ou pela proteína TAU. A maioria das pesquisas até hoje explorou o knockout/knockdown do TREM2; foi demonstrado que diferentes mutações no TREM2 associadas à DA influenciam os níveis do TREM2 de maneira diferente. Mais pesquisas relacionadas às mutações identificadas no TREM2 e usando modelos transgênicos são necessárias ${ }^{39}$.

O receptor 5-hidroxitriptamina 6 (5 HTR6) foi investigado como um possível alvo teraupêtico na sitomatologia da DA, a ser adicionado às terapias atualmente aprovadas pela Food and Drug Administration (FDA): os inibidores da colinesterase e o antagonista do receptor NMDA. A maioria das pesquisas têm sido conduzidas com antagonistas seletivos do 5 HTR6. Esses antagonistas atuam modulando os níveis de glutamato e GABA e, consequentemente, aumentando as concentrações de dopamina, ACh e norepinefrina no cérebro, todos comprometidos na DA. Agonistas do 5 HTR6 também demonstraram desempenhar efeitos pró-cognitivos, de forma que ensaios com agonistas parciais ou inversos podem produzir efeitos cognitivos promissores ${ }^{40}$.

Fortes evidências a respeito da participação das alterações no sistema endocanabinoide (SEC) na patogênese da DA levantaram questões sobre o desenvolvimento de novas abordagens terapêuticas para DA com base na regulação endocanabinoide. O ECS é composto por um conjunto relativamente amplo de receptores, ligantes endógenos e enzimas, que estão envolvidos na patogênese da DA. O receptor canabinoide tipo 2 é superexpresso na micróglia ativada; no entanto, o papel do receptor canabinoide tipo 1 (CB1R) não é claro. Resultados contraditórios de estudos sobre DA em humanos post-mortem mostram mudanças na regulação do receptor ou status de CB1R inalterado. Além disso, estudos pré-clínicos com modelos animais de DA também produziram resultados contraditórios ${ }^{41}$.

Demonstrou-se que o receptor $\gamma$ ativado por proliferador de peroxissomo (PPARY) regula a transcrição de numerosos genes que desempenham papéis-chave na diferenciação de adipócitos, inflamação, resposta imune, sensibilidade à insulina e metabolismo de lipídios e glicose. As vias governadas pelo PPARy se sobrepõem, até certo ponto, às vias biológicas implicadas na patogênese da DA de acordo com diversas evidências. Além disso, O PPARy regula a expressão de sete genes associados à DA, incluindo APOE. Foi demonstrado que o PPARy pode tanto ativar como reprimir a transcrição, em formas dependentes ou independentes de ligandos. Estudos utilizando modelos animais de Alzheimer sugeriram que o PPARy exerce efeitos diretos e indiretos no metabolismo da proteína APP42.

O receptor do tipo NOD contendo um domínio de pirina do tipo 3 (NLRP3) é o membro mais importante da família NLR. É importante ressaltar que a proteína beta-amiloide pode ativar o inflamassoma e aumentar a expressão dos genes NLRP3, caspase1 e IL1- $\beta$; a via do inflamassoma foi mais ativada no grupo de Alzheimer que recebeu uma dieta rica em gordura ${ }^{43}$. Konishi et al. sugeriram a participação do receptor alfa da família GDNF (GRF) na DA, podendo ele exercer um papel na indução de efeitos biológicos nos neurônios corticais envelhecidos. O GDNF foi capaz de promover a sobrevivência celular e a extensão das neurites apenas nos neurônios expressando o GFR1 ${ }^{49}$.

Entre os estudos avaliados, é importante destacar as famílias e as localizações dos receptores neurais envolvidos com a DA, além das principais funções dessas proteínas que podem estar associadas com a doença. Na figura 2, pode-se observar que os receptores de transcrição nuclear foram os mais estudados, correspondendo a mais de $37 \%$ das pesquisas consideradas no artigo. O receptor acoplado à proteína $\mathrm{G}$ também foi bastante pesquisado, correspondendo a aproximadamente $18,52 \%$ dos trabalhos. Juntos, eles correspondem a mais de $55 \%$ dos receptores analisados. É importante ressaltar que a maioria dos artigos avaliou apenas um único receptor; poucos ampliaram as análises para duas ou mais proteínas, possivelmente devido à elevada complexidade das técnicas utilizadas nas pesquisas (Figura 3).

Adicionalmente, pode-se constatar que o córtex cerebral sobressaiu às outras regiões do sistema nervoso, com uma proporção superior a 30\% quando comparado a outros tecidos envolvidos com a doença neurodegenerativa (Figura 4). A área física compreendida pelo córtex cerebral, a sua complexidade e o seu envolvimento com diversas funções relevantes na DA provavelmente justifica esse resultado. Apesar da pequena região compreendida pelo hipocampo, recep- 
tores relacionados com a DA expressam-se em grande proporção nesse tecido (23,61\%), corroborando evidências já estabelecidas na literatura de que essa região é significativamente afetada na DA. Enquanto o córtex cerebral está principalmente envolvido na tomada de decisões, pensamento subjetivo, avaliação das consequências de ação, percepção e atenção, o hipocampo está diretamente relacionado com a memória. Apesar de o hipotálamo ter sido relacionado com apenas 2,8\% dos receptores, sabe-se que a DA está bastante associada com modificações nos padrões emocionais, no entanto isso depende do estágio no qual a doença se encontra.

A maior parte dos receptores estudados $(73,1 \%)$ se expressa em mais de uma região; apenas sete tipos de receptores $(26,9 \%)$ mostraram se expressar somente em um tecido, evidenciando o acometimento de várias regiões cerebrais pela DA. Entre esses sete receptores, seis $(85,7 \%)$ compreenderam o córtex e um (14,3\%), o hipocampo. Adicionalmente, seis pesquisas (23,07\%) destacaram a micróglia como principal tipo celular no qual o receptor se expressa, destacando a

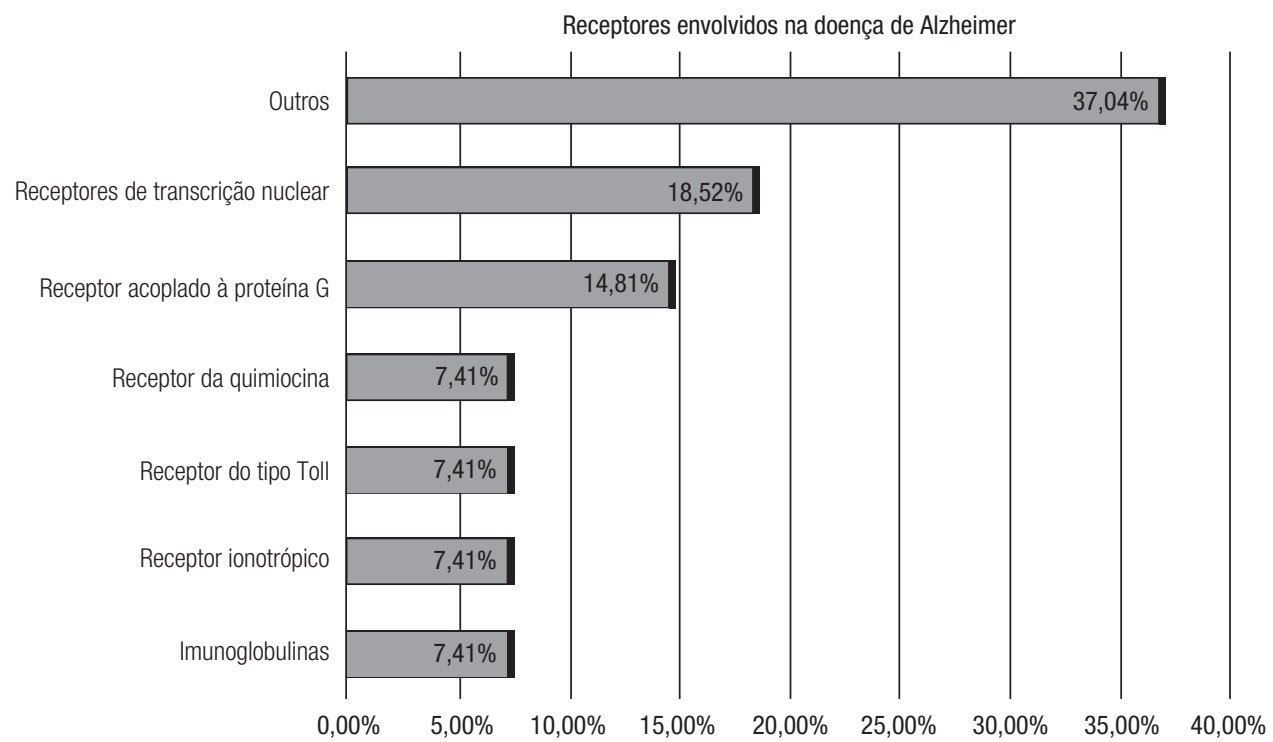

Figura 2. Distribuição das famílias de receptores neurais envolvidas na DA e consideradas nas pesquisas. As principais famílias de receptores consideradas nas pesquisas foram: receptores de transcrição nuclear, receptores acoplados à proteína G, receptores da quimiocina, receptores do tipo Toll, receptores ionotrópicos e imunoglobulinas, respectivamente.

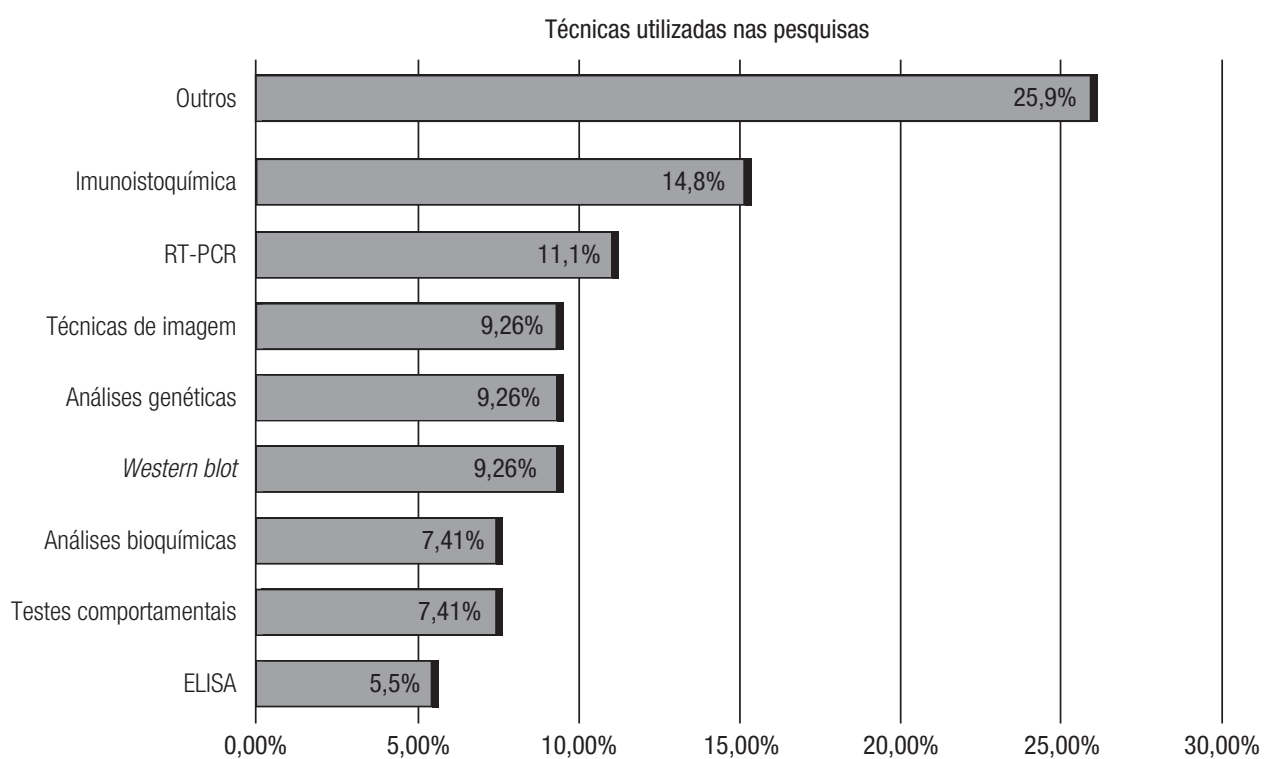

Figura 3. Distribuição das técnicas utilizadas nas pesquisas envolvendo os receptores relacionados com a DA. As principais técnicas utilizadas foram: imunoistoquímica, PCR em tempo real, técnicas de imagem, análises genéticas, western blot, análises bioquímicas, testes comportamentais e ELISA, respectivamente. 
relevância desse tipo celular na DA, especialmente na remoção de peptídeos tóxicos comuns na patologia em questão.

As principais funções dos receptores envolvidos na DA também foram avaliadas (Figura 5). Pode-se perceber que os receptores estudados estão inseridos em diversas vias metabólicas, as quais podem estar relacionadas direta ou indiretamente com a doença. A eliminação da APP ou o bloqueio de vias relacionadas à síntese dessa proteína foi a principal função observada entre os artigos incluídos na pesquisa, compreendendo $15,15 \%$ dos estudos. De fato, uma forma de induzir a DA em animais de laboratório é por meio da administração de peptídeos amiloides $\beta$ (os quais formam a proteína APP). Esses peptídeos afetam principalmente $\mathrm{o}$ neocórtex e o hipocampo, corroborando os achados anteriores (Figura 4), e causam toxicidade, disfunção cognitiva e outras alterações comportamentais ${ }^{32}$.

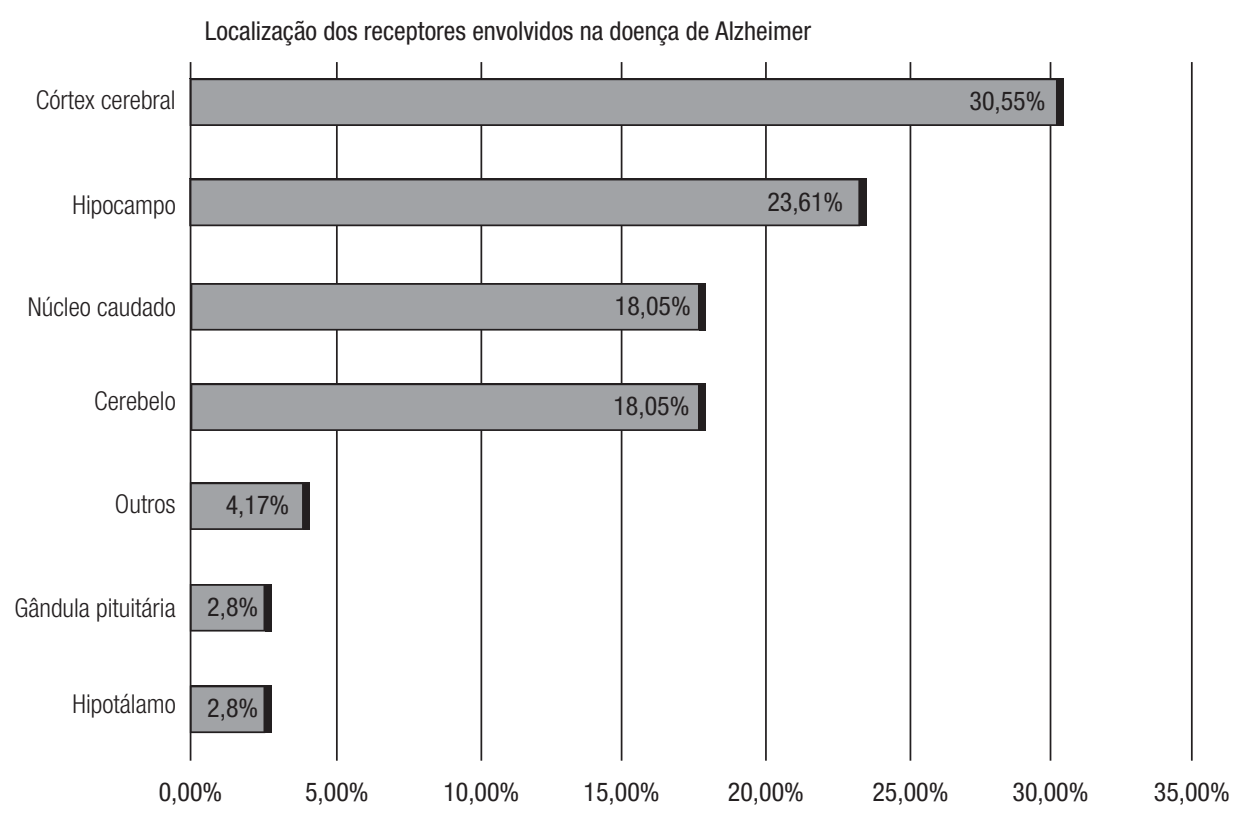

Figura 4. Distribuição das localizações dos diferentes tipos de receptores neurais envolvidos na DA consideradas nas pesquisas. As principais regiões do sistema nervoso central consideradas nas pesquisas foram: córtex cerebral, hipocampo, núcleo caudado, cerebelo glândula pituitária e hipotálamo, respectivamente.

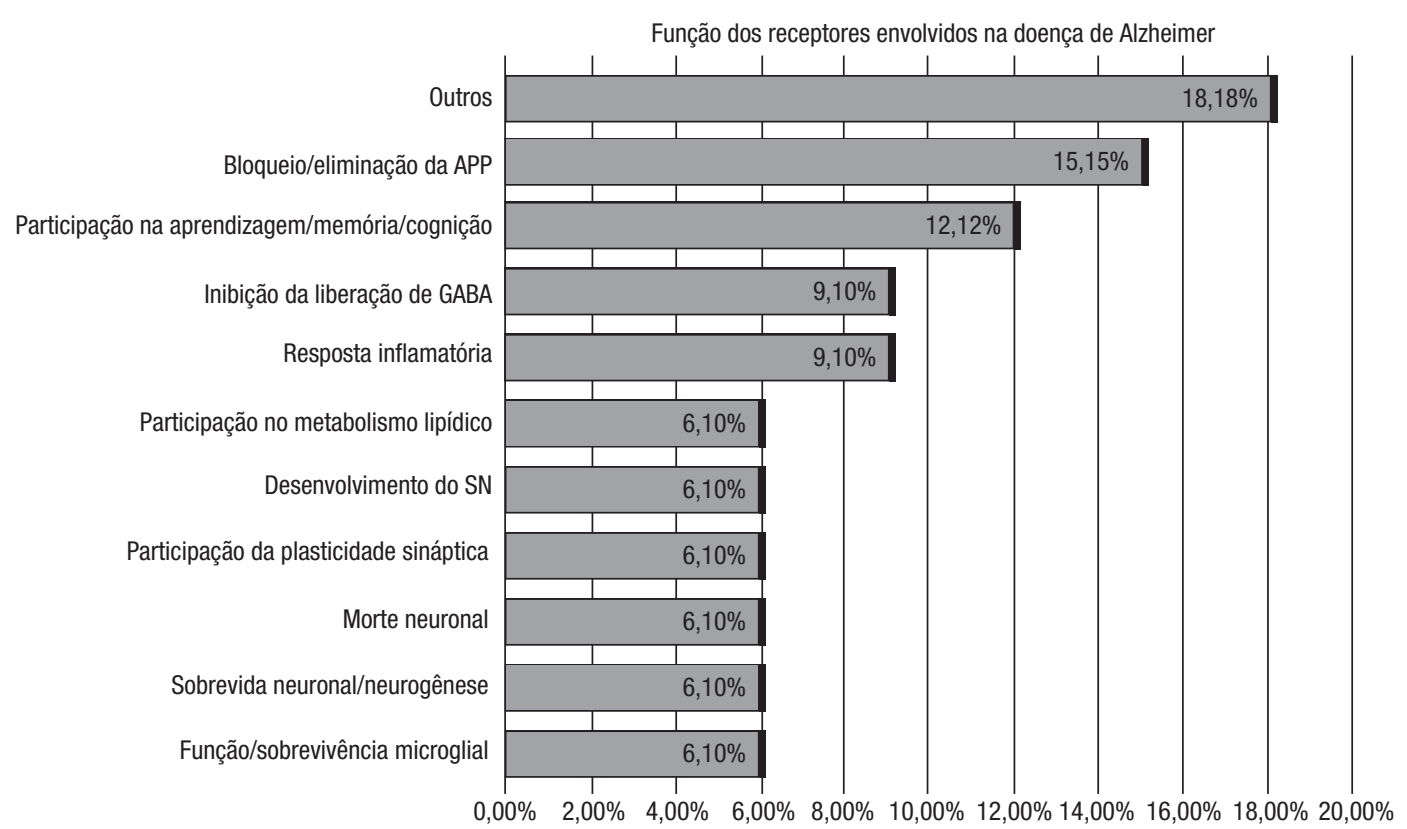

Figura 5. Distribuição das funções dos receptores neurais envolvidos na DA consideradas nas pesquisas. As principais funções dos receptores consideradas nas pesquisas foram: bloqueio ou eliminação da proteína beta-amiloide, participação nos processos de aprendizagem e/ou memória e/ou cognição, inibição da liberação do neurotransmissor inibitório GABA, envolvimento na resposta inflamatória, participação no metabolismo lipídico, influência no desenvolvimento do sistema nervoso, participação na plasticidade sináptica, contribuição para a morte neuronal, influência na sobrevida neuronal ou na sobrevida microglial, respectivamente. 
Muitos receptores também estão envolvidos diretamente em funções cognitivas, memória e/ou aprendizado $(12,12 \%)$. Vale destacar que 15 receptores $(57,7 \%)$ estiveram associados com uma função específica relacionada com a DA, enquanto 11 receptores (42,3\%) estiveram associados com duas ou mais dessas funções. As funções relacionadas com a plasticidade do sistema nervoso, as quais podem incluir a sobrevida neuronal e microglial, o desenvolvimento do sistema nervoso (plasticidade positiva) e a morte neuronal (plasticidade negativa), mostraram-se em iguais proporções. Isso sugere uma participação dos receptores avaliados nas diversas alterações a longo prazo no sistema nervoso (plasticidade a longo prazo).

Outra questão a se discutir diz respeito à idade dos roedores ou humanos envolvidos na pesquisa. Os roedores apresentam idade superior a 6 semanas, ou seja, são animais jovens adultos, induzidos a desenvolver a DA. Algumas pesquisas dão preferência a roedores mais velhos (até 12 meses de vida), uma vez que a degeneração neuronal é mais acentuada. Humanos recrutados para pesquisas envolvendo a DA geralmente apresentam idade superior a 50 anos e podem participar do grupo controle ou experimental. A maioria dos indivíduos com a doença apresenta idade superior a 65 anos (grupo experimental).

Vale ressaltar que pesquisas com humanos são menos realizadas no âmbito dos receptores neurais, quando comparadas ao número de pesquisas envolvendo roedores ou cultura de células, uma vez que determinadas análises do tecido cerebral não são possíveis nesses indivíduos (com exceção de análises post-mortem). Além disso, pesquisas com humanos são mais suscetíveis a fatores externos, tais como tratamento, alimentação e desistência ou morte por parte dos participantes. Experimentos com humanos representaram apenas 28\% das pesquisas, incluindo indivíduos da China, Espanha, Brasil, América do Norte e diversas regiões da Europa. Nesse contexto, alguns autores tendem a unir dois ou mais modelos de estudo. Entre as pesquisas, 50\% utilizaram apenas um modelo, enquanto os outras 50\% utilizaram dois ou mais modelos, e apenas uma utilizou três modelos.

Dessa forma, a maior parte das pesquisas envolvendo receptores associados com a DA utiliza modelos animais, em especial, roedores (40\%), incluindo diferentes linhagens de ratos (16\%) ou camundongos (24\%) (Figura 6). Dentre os testes que utilizam animais em pesquisas relacionadas com a DA, destacam-se o teste de reconhecimento de objetos e o teste da aprendizagem à evitação passiva ${ }^{33}$. Apesar de os ratos possuírem vantagens tais como a grande semelhança genética com os humanos, além do tamanho das estruturas encefálicas, as quais facilitam o desenvolvimento de técnicas como a imunoistoquímica $(\mathrm{IHQ})^{32,43}$, os camundongos ainda são os modelos mais utilizados em estudos genéticos ${ }^{56}$. Em relação aos ratos, a linhagem Wistar é utilizada com frequência e com facilidade em testes comportamentais. Culturas de células (32\% das pesquisas) geralmente são associadas aos modelos animais. A associação de humanos e cultura de células ou humanos e roedores é menos comum, mas também ocorre.

Em relação às técnicas mais utilizadas, a $\mathrm{HQ}$ destacou-se com 14,8\% das técnicas (Figura 3). Resumidamente, a IHQ é uma técnica comum usada no diagnóstico morfológico e no estudo da patogênese da doença. A técnica e a interpretação adequada de um ensaio imunoistoquímico são de extrema importância, e a IHQ requer cuidados em cada etapa do procedimento, incluindo os processos de lavagem, a fixação dos tecidos em lâminas, os anticorpos utilizados e a quantidade dos reagentes ${ }^{57}$. A vizualização dos neurônios em cortes do cérebro de animais pela IHQ permite estudar se a expressão ou inibição de determinado receptor está envolvida com neurogênese ou morte neuronal, por exemplo (funções associadas com alguns receptores) (Figura 5). Vale resaltar também que a elevada porcentagem dos estudos que utilizam a IHQ pode estar atrelada à preferência dos animais como modelos de estudo, uma vez que essa técnica é utilizada

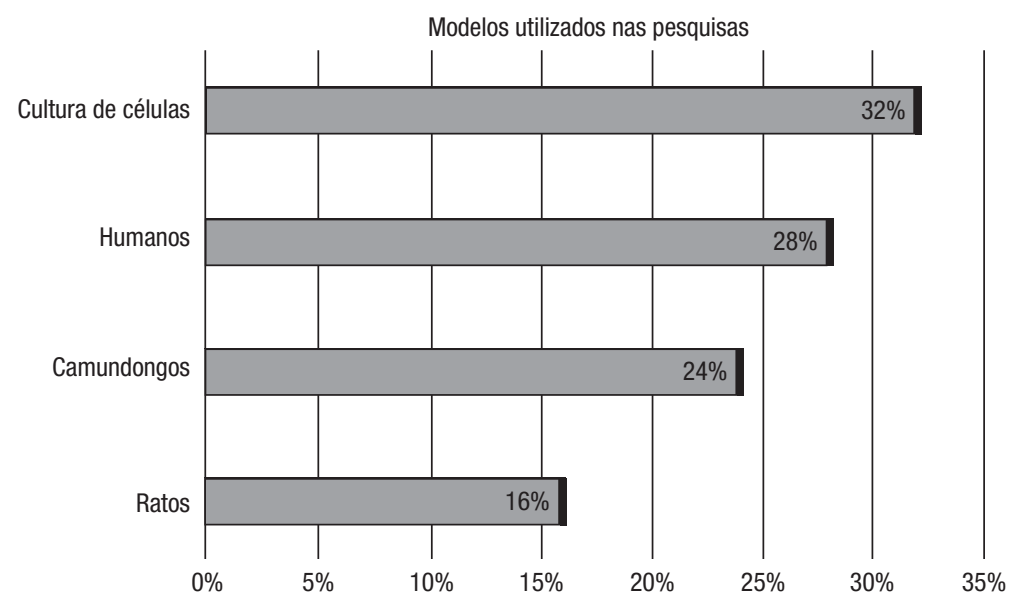

Figura 6. Distribuição dos modelos utilizados nas pesquisas envolvendo os receptores relacionados com a DA. Os principais modelos utilizados foram: roedores (camundongos e ratos), cultura de células e humanos, respectivamente. 
principalmente em roedores. A segunda técnica mais utilizada $(11,1 \%)$ consistiu na reação em cadeia de polimerase em tempo real (RT-PCR), uma das técnicas mais difundidas e confiáveis usadas para mensurar a expressão gênica.

Em relação ao tamanho da amostra ou número amostral, pesquisas evolvendo animais necessitam da aprovação pelo Comitê de Ética, que geralmente não permite a utilização de grupos com mais de 10 animais. Dessa forma, a depender da experimentação (número de grupos ou técnicas utilizadas), o número de animais varia; no entanto, 10 animais por grupo (ou às vezes menos) são suficientes para uma significância nos testes estatísticos. Já as pesquisas envolvendo humanos geralmente envolvem centenas ou até milhares de indivíduos, com exceção das análises post-mortem, as quais requerem doações por parte de instituições especializadas localizadas em países como os Estados Unidos.

Em relação às limitações de estudo, deve-se destacar o razoável número de artigos encontrados com as informações de interesse (utilizadas para a elaboração dos gráficos). Todos os artigos utilizados neste estudo necessitavam conter todas essas informações. Além disso, os receptores não poderiam estar duplicados nas análises, ou seja, diversos artigos tratavam do mesmo receptor envolvido com a DA. Nesse sentido, selecionamos o artigo com maior fator de impacto. Adicionalmente, as análises de proporção não foram afetadas pelo número de artigos utilizados, uma vez que várias técnicas, modelos, funções e localizações dos receptores foram incluídos em muitos artigos. Nesse contexto, novas pesquisas envolvendo receptores associados com a DA são necessárias, principalmente quando elas estão relacionadas com o diagnóstico e o tratamento da doença. Outra limitação encontrada refere-se ao número amostral e à idade dos animais ou humanos parti- cipantes; no entanto, apenas três artigos não informaram um desses dados, o que não interferiu em nossas análises.

Por fim, pode-se perceber que a maior parte das pesquisas avaliaram receptores relacionados com efeitos protetores na DA (Figura 6). Dezesseis receptores (59, 26\%) estiveram associados a um prognóstico positivo na doença, enquanto 11 receptores (40,74\%) estiveram associados a um prognóstico negativo (os receptores CPE e Sglll foram avaliados em um único artigo). Dessa forma, vale a pena focar nesses receptores que podem estar associados com a piora do prognóstico na DA, com o objetivo de prevenir quaisquer induções nesses receptores (o que pode ocorrer por meio de alguns fármacos, por exemplo), especialmente em indivíduos com DA. Em outro trabalho, o nosso grupo de pesquisa avaliou algumas proteínas relacionadas com a DA e os níveis de vitamina D. Verificou-se que a vitamina $D$, o receptor da vitamina $D$, a proteína klotho e a proteína PTEN estavam relacionados com um prognóstico favorável, enquanto as proteínas RAGE, APP e mTORC1 estiveram relacionadas com um prognóstico desfavorável na DA ${ }^{51}$.

\section{CONCLUSÕES}

Esta revisão permitiu uma percepção global sobre os receptores neuronais envolvidos na DA, por meio da utilização de uma metodologia sistemática. A maioria dos estudos analisados mostrou alguma perspectiva de aplicação clínica. Os artigos apresentam diferentes famílias e funções dos receptores neurais, com o objetivo comum de avaliar uma possível participação desses receptores na DA. Observou-se que os receptores de transcrição nuclear foram os mais estudados, correspondendo a mais de $37 \%$ das pesquisas con-

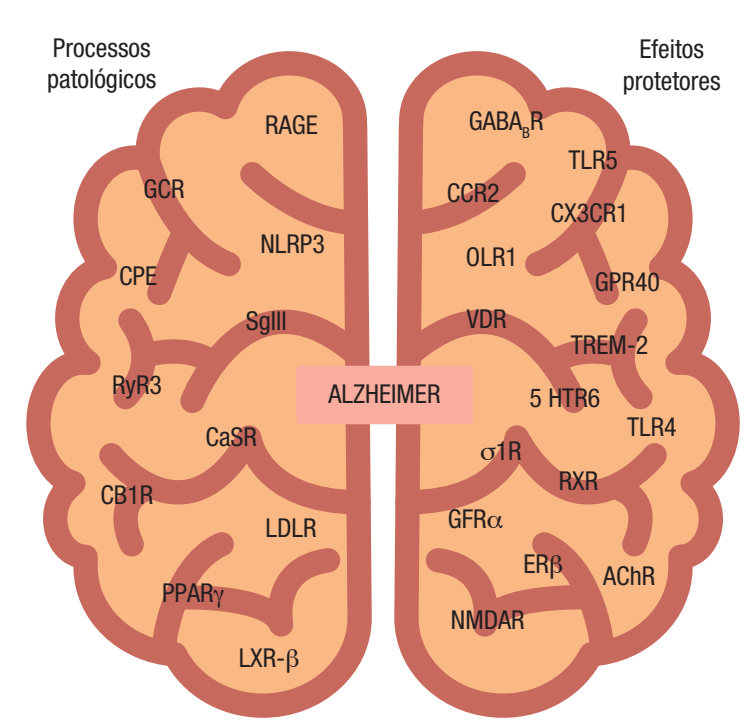

Figura 7. Receptores neurais envolvidos com os processos patológicos e com os efeitos protetores na doença de Alzheimer. De um lado, encontram-se 11 receptores envolvidos com os processos patológicos e do outro, 16 receptores que desempenham efeitos protetores na DA. Alguns desses efeitos estão descritos nas tabelas 2 e 3 e resumidos na figura 5. 
sideradas no artigo. Mais de 55\% desses receptores neurais se expressam no córtex cerebral e hipocampo. Além disso, a micróglia consistiu no principal tipo celular no qual os receptores estão presentes. A eliminação da APP ou o bloqueio de vias relacionadas à síntese dessa proteína caracterizou-se como principal função desempenhada por esses receptores. De fato, a maior parte das pesquisas avaliou os receptores relacionados com efeitos protetores na DA. Por fim, os modelos animais foram os mais utilizados e, dentre as diversas técnicas utilizadas nas pesquisas, destacou-se a IHQ. Por meio da análise dos artigos, foi possível observar que a produção científica mundial sobre os receptores específicos envolvidos na DA tem ganhado cada vez mais importância, com informações relevantes para os estudos que incluem o diagnóstico, prevenção e até tratamento da DA. Dessa forma, compilar esses estudos, mostrando suas similaridades, diferenças e principais achados, é de relevância para novos estudos nesse campo científico.

Tabela 3. Pesquisas relacionadas aos receptores neurais envolvidos na DA realizadas

\begin{tabular}{|c|c|c|c|c|}
\hline Artigo e base de dados & Modelo & Técnicas & Idade & № amostral \\
\hline $\begin{array}{l}\text { Oh et al., } 2018^{32} \\
\text { PubMed }\end{array}$ & Ratos (Sprague Dawley) & qRT-PCR e ELISA & 7 semanas & Não informado \\
\hline $\begin{array}{l}\text { Almasi et al., } 2018^{33} \\
\text { PubMed }\end{array}$ & Ratos machos (Wistar) & $\begin{array}{l}\text { Testes comportamentais } \\
\text { e histopatologia }\end{array}$ & $\begin{array}{l}\text { Não } \\
\text { informado }\end{array}$ & 70 animais \\
\hline $\begin{array}{l}\text { Chakrabarty et al., } 2018^{34} \\
\text { PubMed }\end{array}$ & $\begin{array}{l}\text { Camundongos } \\
\text { (C57B6/C3H), } \\
\text { humanos (América do Norte) } \\
\text { e cultura de células }\end{array}$ & $\begin{array}{l}\text { Immunoblotting, ELISA, } \\
\text { imunoistoquímica, testes } \\
\text { comportamentais, RNAseq, } \\
\text { análises genéticas e ensaios de } \\
\text { fagocitose }\end{array}$ & $\begin{array}{l}\text { Pacientes: } \\
>50 \text { anos } \\
\text { Animais: } \\
12 \text { semanas }\end{array}$ & $\begin{array}{l}65 \text { humanos } \\
63 \text { animais }\end{array}$ \\
\hline $\begin{array}{l}\text { Kootar et al., } 2018^{36} \\
\text { PubMed }\end{array}$ & $\begin{array}{l}\text { Cultura de células } \\
\text { e camundongos (GRlox/lox) }\end{array}$ & $\begin{array}{l}\text { Immunoblotting, técnicas de } \\
\text { imagem, } \\
\text { imunoistoquímica e eletrofisiologia }\end{array}$ & 8 semanas & 3 animais \\
\hline $\begin{array}{l}\text { Wang et al., } 2018^{37} \\
\text { PubMed }\end{array}$ & Humanos (China) & Análises genéticas & $>69$ anos & 2.338 humanos \\
\hline $\begin{array}{l}\text { Takkinen et al., } 2018^{41} \\
\text { PubMed }\end{array}$ & $\begin{array}{l}\text { Camundongos } \\
\text { (TG APP/PS1) }\end{array}$ & $\begin{array}{l}\text { Técnicas de imagem, } \\
\text { análises bioquímicas, estudos de } \\
\text { bloqueio, } \\
\text { imunoistoquímica e western blot }\end{array}$ & 6 semanas & 103 animais \\
\hline $\begin{array}{l}\text { Barrera et al., } 2018^{42} \\
\text { PubMed }\end{array}$ & Cultura de células & Análises genéticas & $\begin{array}{l}\text { Não se } \\
\text { aplica }\end{array}$ & Não se aplica \\
\hline $\begin{array}{l}\text { Mirzaei et al., } 2018^{43} \\
\text { PubMed }\end{array}$ & Ratos (Wistar) & $\begin{array}{l}\text { Testes comportamentais, qRT-PCR, } \\
\text { análises bioquímicas, ELISA, } \\
\text { histopatologia e imunoistoquímica }\end{array}$ & 8 semanas & 120 animais \\
\hline $\begin{array}{l}\text { Yeo et al., } 2018^{44} \\
\text { PubMed }\end{array}$ & $\begin{array}{l}\text { Camundongos (PRDX6 Tg) e } \\
\text { cultura de células }\end{array}$ & $\begin{array}{l}\text { Imunoistoquímica, western blot, } \\
\text { qRT-PCR e microarray }\end{array}$ & 10 semanas & 8 animais \\
\hline $\begin{array}{l}\text { Valencia et al., } 2018^{45} \\
\text { PubMed }\end{array}$ & Cultura de células & $\begin{array}{l}\text { Análises bioquímicas e } \\
\text { estudos computacionais }\end{array}$ & $\begin{array}{l}\text { Não se } \\
\text { aplica }\end{array}$ & Não se aplica \\
\hline $\begin{array}{l}\text { Cramer et al., } 2012^{16} \\
\text { PubMed }\end{array}$ & $\begin{array}{l}\text { Camundongos } \\
\text { (APP/PS1) e } \\
\text { cultura de células }\end{array}$ & $\begin{array}{l}\text { Imunoistoquímica, western blot, } \\
\text { qRT-PCR, técnicas de imagem, testes } \\
\text { comportamentais e eletrofisiologia }\end{array}$ & 11 meses & 90 animais \\
\hline $\begin{array}{l}\text { Wanget al., } 2012^{46} \\
\text { PubMed }\end{array}$ & $\begin{array}{l}\text { Humanos (Europa) } \\
\text { e cultura de células }\end{array}$ & Análises genéticas e RT-PCR & $>66$ anos & 988 humanos \\
\hline $\begin{array}{l}\text { Plá et al., } 2012^{47} \\
\text { PubMed }\end{array}$ & $\begin{array}{l}\text { Humanos (Espanha) e } \\
\text { camundongos machos } \\
\text { (APPswe/PS1dE9) }\end{array}$ & $\begin{array}{l}\text { Imunoistoquímica, western blot e } \\
\text { microscopia eletrônica }\end{array}$ & $\begin{array}{l}\text { Humanos: } \\
>49 \text { anos } \\
\text { Animais: } \\
6 \text { meses }\end{array}$ & $\begin{array}{l}24 \text { humanos } \\
\text { (post-mortem) } \\
8 \text { animais }\end{array}$ \\
\hline $\begin{array}{l}\text { Konishi et al., } 2014^{49} \\
\text { PubMed }\end{array}$ & $\begin{array}{l}\text { Humanos (Estados Unidos) } \\
\text { e cultura de células }\end{array}$ & $\begin{array}{l}\text { Imunoistoquímica, testes de } \\
\text { viabilidade } \\
\text { celular, técnicas de imagem, RT-PCR, } \\
\text { western blot e análises bioquímicas }\end{array}$ & $>76$ anos & $\begin{array}{l}12 \text { humanos } \\
\text { (post-mortem) }\end{array}$ \\
\hline $\begin{array}{l}\text { Waqar e Batool, } 2017^{53} \\
\text { SciELO }\end{array}$ & $\begin{array}{l}\text { Humanos e ratos } \\
\text { (Rattus norvegicus) }\end{array}$ & $\begin{array}{l}\text { Estudos computacionais } \\
\text { (bioinformática) }\end{array}$ & $\begin{array}{l}\text { Não se } \\
\text { aplica }\end{array}$ & Não informado \\
\hline $\begin{array}{l}\text { Oliveira et al., } 2017^{54} \\
\text { SciEL0 }\end{array}$ & Humanos (Brasil) & $\begin{array}{l}\text { Técnicas de imagem e análises } \\
\text { genéticas }\end{array}$ & $>67$ anos & 201 humanos \\
\hline
\end{tabular}

Dados extraídos dos artigos publicados: Referência (autor e ano), modelo (animal e/ou humano e/ou cultura de célulass), técnicas utilizadas na experimentação e idade dos animais ou humanos envolvidos na pesquisa. 


\section{CONTRIBUIÇÕES INDIVIDUAIS}

Alice Barros Câmara - Contribuiu substancialmente para a concepção e o design ou análise e interpretação dos dados; contribuiu substancialmente para redigir o artigo ou revisá-lo criticamente para conteúdo intelectual importante; e deu a aprovação final da versão a ser publicada.

\section{CONFLITO DE INTERESSES}

A autora declara que não existe conflito de interesses em relação à publicação deste documento.

\section{REFERÊNCIAS}

1. Ribeiro AFC, Serakides R, Nunes VA, Silva CM, Ocarino NM. Osteoporosis and the endocrine disturbances of thyroid and gonads. Ara Bras Endocrinol Metab. 2003;47(3):228-36.

2. Caselli RJ, Reiman EM. Characterizing the preclinical stages of Alzheimer's disease and the prospect of presymptomatic intervention. J Alzheimers Dis. 2013;33 Suppl 1:S405-16.

3. Francis PT. The interplay of neurotransmitters in Alzheimer's disease. CNS Spectr. 2005;10(11 Suppl 18):6-9.

4. Vinters HV. Emerging concepts in Alzheimer's disease. Annu Rev Pathol. 2015;10:291-319.

5. Ferrer I. Defining Alzheimer as a common age-related neurodegenerative process not inevitably leading to dementia. Prog Neurobiol. 2012;97(1):38-51.

6. Serrano-Pozo A, Frosch MP, Masliah E, Hyman BT. Neuropathological alterations in Alzheimer disease. Cold Spring Harb Perspect Med. 2011;1(1):a006189.

7. Kocahan S, Doğan Z. Mechanisms of Alzheimer's disease pathogenesis and prevention: the brain, neural pathology, N-methyl-D-aspartate receptors, tau protein and other risk factors. Clin Psychopharmacol Neurosci. 2017;15(1):1-8.

8. Tan CC, Yu JT, Wang HF, Tan MS, Meng XF, Wang C, et al. Efficacy and safety of donepezil, galantamine, rivastigmine, and memantine for the treatment of Alzheimer's disease: a systematic review and meta-analysis. J Alzheimers Dis. 2014;41(2):615-31.

9. Prince M, Wimo A, Guerchet M, Ali GC, Wu YT, Prina M. World Alzheimer Report 2015: The Global Impact of Dementia: An Analysis of Prevalence, Incidence, Cost and Trends. Alzheimer's Dis Int. 2015.

10. Xiong JY, Li SC, Sun YX, Zhang XS, Dong ZZ, Zhong P, et al. Long-term treadmill exercise improves spatial memory of male APPswe/PS1dE9 mice by regulation of BDNF expression and microglia activation. Biol Sport. 2015;32(4):295-300.

11. Qiu C, Kivipelto M, von Strauss E. Epidemiology of Alzheimer's disease: occurrence, determinants, and strategies toward intervention. Dialogues Clin Neurosci. 2009;11(2):111-28.

12. Burgos-Ramos E, Hervás-Aguilar A, Aguado-Llera D, Puebla-Jiménez L, HernándezPinto AM, Barrios V, et al. Somatostatin and Alzheimer's disease. Mol Cell Endocrinol. 2008;286(1-2):104-11.

13. Wenk GL. Neuropathologic changes in Alzheimer's disease: potential targets for treatment. J Clin Psychiatry. 2006;67 Suppl 3:3-7; quiz 23.

14. Zuccato C, Cattaneo E. Brain-derived neurotrophic factor in neurodegenerative diseases. Nat Rev Neurol. 2009:5(6):311-22.

15. Woodruff-Pak DS, Gould TJ. Neuronal nicotinic acetylcholine receptors: involvement in Alzheimer's disease and schizophrenia. Behav Cogn Neurosci Rev. 2002;1(1):5-20.

16. Cramer PE, Cirrito JR, Wesson DW, Lee CY, Karlo JC, Zinn AE, et al. ApoE-directed therapeutics rapidly clear $\beta$-amyloid and reverse deficits in AD mouse models. Science, 2012;335(6075):1503-6.

17. Leroy K, Ando K, Laporte V, Dedecker R, Suain V, Authelet M, et al. Lack of tau proteins rescues neuronal cell death and decreases amyloidogenic processing of APP in APP/PS1 mice. Am J Pathol. 2012;181(6):1928-40.
18. Abdi F, Quinn JF, Jankovic J, McIntosh M, Leverenz JB, Peskind $E$, et al. Detection of biomarkers with a multiplex quantitative proteomic platform in cerebrospinal fluid of patients with neurodegenerative disorders. J Alzheimers Dis. 2006;9(3):293-348.

19. Perrin RJ, Craig-Schapiro R, Malone JP, Shah AR, Gilmore P, Davis AE, et al. Identification and validation of novel cerebrospinal fluid biomarkers for staging early Alzheimer's disease. PLoS One. 2011;6(1):e16032

20. Woronowicz A, Cawley NX, Chang SY, Koshimizu H, Phillips AW, Xiong ZG, et al. Carboxypeptidase E knockout mice exhibit abnormal dendritic arborization and spine morphology in central nervous system neurons. J Neurosci Res. 2010;88(1):64-72.

21. Woronowicz A, Koshimizu H, Chang SY, Cawley NX, Hill JM, Rodriguiz RM, et al. Absence of carboxypeptidase E leads to adult hippocampal neuronal degeneration and memory deficits. Hippocampus. 2008;18(10):1051-63.

22. Govindpani K, Calvo-Flores Guzmán B, Vinnakota C, Waldvogel HJ, Faull RL, Kwakowsky A. Towards a Better understanding of GABAergic remodeling in Alzheimer's disease. Int J Mol Sci. 2017;18(8). pii: E1813.

23. Kwakowsky A, Calvo-Flores Guzmán B, Govindpani K, Waldvogel HJ, Faull RL. Gammaaminobutyric acid $A$ receptors in Alzheimer's disease: highly localized remodeling of a complex and diverse signaling pathway. Neural Regen Res. 2018;13(8):1362-3.

24. Lanctôt KL, Herrmann N, Mazzotta P, Khan LR, Ingber N. GABAergic function in Alzheimer's disease: evidence for dysfunction and potential as a therapeutic target for the treatment of behavioural and psychological symptoms of dementia. Can J Psychiatry. 2004;49(7):439-53.

25. Fuhrer TE, Palpagama TH, Waldvogel HJ, Synek BJL, Turner C, Faull RL, et al. Impaired expression of GABA transporters in the human Alzheimer's disease hippocampus, subiculum, entorhinal cortex and superior temporal gyrus. Neuroscience. 2017;351:108-18.

26. Louzada PR, Paula Lima AC, Mendonca-Silva DL, Noël F, De Mello FG, Ferreira ST. Taurine prevents the neurotoxicity of beta-amyloid and glutamate receptor agonists: activation of GABA receptors and possible implications for Alzheimer's disease and other neurological disorders. FASEB J. 2004:18(3):511-8

27. Brawek B, Chesters R, Klement D, Müller J, Lerdkrai C, Hermes M, et al. A bell-shaped dependence between amyloidosis and GABA accumulation in astrocytes in a mouse model of Alzheimer's disease. Neurobiol Aging. 2018;61:187-97.

28. Kwakowsky A, Calvo-Flores Guzmán B, Pandya M, Turner C, Waldvogel HJ, Faull RL. GABA receptor subunit expression changes in the human Alzheimer's disease hippocampus, subiculum, entorhinal cortex and superior temporal gyrus. J Neurochem. 2018;145(5):374-92.

29. Calvo-Flores Guzmán B, Vinnakota C, Govindpani K, Waldvogel HJ, Faull RLM, Kwakowsky A. The GABAergic System as a Therapeutic Target for Alzheimer's Disease. J Neurochem. 2018:146(6):649-69.

30. Konishi H, Kiyama H. Microglial TREM2/DAP12 signaling: a double-edged sword in neural diseases. Front Cell Neurosci. 2018;12:206

31. The Human Protein Atlas. Disponível em: https://www.proteinatlas.org/. Acesso em: 20 nov. 2018.

32. Oh S, Son M, Choi J, Lee S, Byun K. sRAGE prolonged stem cell survival and suppressed RAGE-related inflammatory cell and T Iymphocyte accumulations in an Alzheimer's disease model. Biochem Biophys Res Commun. 2018;495(1):807-13.

33. Almasi A, Zarei M, Raoufi S, Sarihi A, Salehi I, Komaki A, et al. Influence of hippocampal $G A B A B$ receptor inhibition on memory in rats with acute $\beta$-amyloid toxicity. Metab Brain Dis. 2018:33(6):1859-67.

34. Chakrabarty P, Li A, Ladd TB, Strickland MR, Koller EJ, Burgess JD, et al. TLR5 decoy receptor as a novel anti-amyloid therapeutic for Alzheimer's disease. J Exp Med. 2018;215(9):2247-64.

35. Guedes JR, Lao T, Cardoso AL, El Khoury J. Roles of Microglial and Monocyte Chemokines and Their Receptors in Regulating Alzheimer's Disease-Associated Amyloid- $\beta$ and Tau Pathologies. Front Neurol. 2018;9:549.

36. Kootar S, Frandemiche ML, Dhib G, Mouska X, Lorivel T, Poupon-Silvestre G, et al. Identification of an acute functional cross-talk between amyloid- $\beta$ and glucocorticoid receptors at hippocampal excitatory synapses. Neurobiol Dis. 2018;118:117-28.

37. Wang ZT, Zhong XL, Tan MS, Wang HF, Tan CC, Zhang W, et al. Association of lectinlike oxidized low density lipoprotein receptor 1 (OLR1) polymorphisms with late-onset Alzheimer disease in Han Chinese. Ann Transl Med. 2018:6(10):172.

38. Chen JJ, Gong YH, He L. Role of GPR40 in pathogenesis and treatment of Alzheimer's disease and type 2 diabetic dementia. J Drug Target. 2019;27(4):347-54. 
39. Deming Y, Li Z, Benitez BA, Cruchaga C. Triggering receptor expressed on myeloid cells 2 (TREM2): a potential therapeutic target for Alzheimer disease?. Expert Opin Ther Targets. 2018;22(7):587-98.

40. Khoury R, Grysman N, Gold J, Patel K, Grossberg GT. The role of 5 HT6-receptor antagonists in Alzheimer's disease: an update. Expert Opin Investig Drugs. 2018;27(6):523-33.

41. Takkinen JS, López-Picón FR, Kirjavainen AK, Pihlaja R, Snellman A, Ishizu T, et al. [18F] FMPEP-d2 PET imaging shows age- and genotype-dependent impairments in the availability of cannabinoid receptor 1 in a mouse model of Alzheimer's disease. Neurobiol Aging. 2018;69:199-208.

42. Barrera J, Subramanian S, Chiba-Falek 0. Probing the role of PPARY in the regulation of late-onset Alzheimer's disease-associated genes. PLoS One. 2018;13(5):e0196943.

43. Mirzaei F, Khazaei M, Komaki A, Amiri I, Jalili C. Virgin coconut oil (VCO) by normalizing NLRP3 inflammasome showed potential neuroprotective effects in Amyloid- $\beta$ induced toxicity and high-fat diet fed rat. Food Chem Toxicol. 2018;118:68-83.

44. Yeo IJ, Park MH, Son DJ, Kim JY, Nam KT, Hyun BK, et al. PRDX6 Inhibits Neurogenesis through Downregulation of WDFY1-Mediated TLR4 Signal. Mol Neurobiol. 2019;56(5):3132-44.

45. Estrada Valencia M, Herrera-Arozamena C, de Andrés L, Pérez C, Morales-García JA, Pérez-Castillo A, et al. Neurogenic and neuroprotective donepezil-flavonoid hybrids with sigma-1 affinity and inhibition of key enzymes in Alzheimer's disease. Eur J Med Chem. 2018:156:534-53.

46. Wang L, Hara K, Van Baaren JM, Price JC, Beecham GW, Gallins PJ, et al. Vitamin D receptor and Alzheimer's disease: a genetic and functional study. Neurobiol Aging. 2012;33(8):1844. e1-9.

47. Plá V, Paco S, Ghezali G, Ciria V, Pozas E, Ferrer I, et al. Secretory sorting receptors carboxypeptidase $E$ and secretogranin III in amyloid $\beta$-associated neural degeneration in Alzheimer's disease. Brain Pathol. 2013;23(3):274-84.
48. Lombardo S, Maskos U. Role of the nicotinic acetylcholine receptor in Alzheimer's disease pathology and treatment. Neuropharmacology. 2015;96(Pt B):255-62.

49. Konishi Y, Yang LB, He P, Lindholm K, Lu B, Li R, et al. Deficiency of GDNF Receptor GFRa1 in Alzheimer's neurons results in neuronal death. J Neurosci. 2014;34(39):13127-38.

50. Zhao L, Woody SK, Chhibber A. Estrogen receptor $\beta$ in Alzheimer's disease: From mechanisms to therapeutics. Ageing Res Rev. 2015;24(Pt B):178-90.

51. Camara AB, de Souza ID, Dalmolin RJS. Sunlight incidence, vitamin D deficiency, and Alzheimer's disease. J Med Food. 2018;21(9):841-8.

52. Chiarini A, Armato U, Liu D, Dal Prà I. Calcium-sensing receptors of human neural cells play crucial roles in Alzheimer's disease. Front Physiol. 2016;7:134.

53. Waqar M, Batool $\mathrm{S}$. In silico analysis of binding interaction of conantokins with NMDA receptors for potential therapeutic use in Alzheimer's disease. J Venom Anim Toxins Incl Trop Dis. 2017;23:42.

54. Oliveira FFD, Chen ES, Smith MC, Bertolucci PH. Associations of cerebrovascular metabolism genotypes with neuropsychiatric symptoms and age at onset of Alzheimer's disease dementia. Rev Bras Psiquiatr. 2017;39(2):95-103.

55. Courtney R, Landreth GE. LXR regulation of brain cholesterol: from development to disease. Trends Endocrinol Metab. 2016;27(6):404-414.

56. Deacon RM. Housing, husbandry and handling of rodents for behavioral experiments. Nat Protoc. 2006;1(2):936-46.

57. Ward JM, Rehg JE. Rodent immunohistochemistry: pitfalls and troubleshooting. Vet Pathol. 2014;51(1):88-101. 